\title{
Regulation of Phospholipid Synthesis in the Yeast Saccharomyces cerevisiae
}

\author{
George M. Carman and Gil-Soo Han \\ Department of Food Science and Rutgers Center for Lipid Research, Rutgers University, New \\ Brunswick, New Jersey 08901
}

George M. Carman: carman@aesop.rutgers.edu; Gil-Soo Han: gshan@rci.rutgers.edu

\section{Abstract}

The yeast Saccharomyces cerevisiae, with its full complement of organelles, synthesizes membrane phospholipids by pathways that are generally common to those found in higher eukaryotes. Phospholipid synthesis in yeast is regulated in response to a variety of growth conditions (e.g., inositol supplementation, zinc depletion, and growth stage) by a coordination of genetic (e.g., transcriptional activation and repression) and biochemical (e.g., activity modulation and localization) mechanisms. Phosphatidate (PA), whose cellular levels are controlled by the activities of key phospholipid synthesis enzymes, plays a central role in the transcriptional regulation of phospholipid synthesis genes. In addition to the regulation of gene expression, phosphorylation of key phospholipid synthesis catalytic and regulatory proteins controls the metabolism of phospholipid precursors and products.

\section{Keywords}

membranes; phosphatidate; inositol; zinc; phosphorylation

\section{INTRODUCTION}

Phospholipids are major structural components of cellular membranes and are essential for vital cellular processes $(1,2)$. Their structure is based on a glycerol-3-phosphate backbone in which fatty acyl groups are esterified to positions 1 and 2 (Figure 1). As amphipathic molecules, they form a bilayer in which integral and peripheral membrane proteins, as well as other complex components, associate (3). In addition, they are reservoirs of second messengers (4), provide precursors for the synthesis of macromolecules (5-9), serve in the modification of membrane association (10), and function as molecular chaperons (11). In the budding yeast, Saccharomyces cerevisiae, which contains a full complement of organelles, phospholipids are synthesized via pathways that are generally common to those found in higher eukaryotic organisms $(12,13)$. Its tractable genetics has facilitated the identification and characterization of nearly all of the structural and regulatory genes that are involved in de novo phospholipid synthesis $(13,14)$. Moreover, the purification and characterization of key enzymes from the organism have led to an understanding of biochemical regulation in phospholipid synthesis $(12,15,16)$. Phospholipid synthesis in yeast is a complex process that is regulated by genetic and biochemical mechanisms $(12,14-20)$, and its regulation is

Copyright $@ 2011$ by Annual Reviews. All rights reserved DISCLOSURE STATEMENT

The authors are not aware of any affiliations, memberships, funding, or financial holdings that might be perceived as affecting the objectivity of this review. 
interrelated with the synthesis and regulation of other major lipid classes that include fatty acids, triacylglycerol (TAG), sterols, and sphingolipids $(12,21-25)$. In this review, the focus is on the interrelationships between the genetic and biochemical regulations of the synthesis of the major phospholipids in $S$. cerevisiae. The way that yeast gene and protein terms are named is described in the sidebar Yeast Gene/Protein Nomenclature.

\section{PATHWAYS FOR THE SYNTHESIS OF THE MAJOR PHOSPHOLPIDS}

The major phospholipids found in the cellular membranes of $S$. cerevisiae include phosphatidylcholine (PC), phosphatidylethanolamine (PE), phosphatidylinositol (PI), and phosphatidylserine (PS) (26-29). Phosphatidylglycerol (PG) and cardiolipin (CL) are also major phospholipids in mitochondrial membranes $(26,28,29)$. Minor phospholipids include intermediates: phosphatidate (PA); CDP-diacylglycerol (CDP-DAG) phosphatidylmonomethylethanolamine and phosphatidyldimethylethanolamine; the D-3, D-4, and D-5 polyphosphoinositides; lysophospholipids; and diacylglycerol (DAG) pyrophosphate $(26,30,31)$. The most common fatty acids esterified to the glycerophosphate backbone of these lipids include palmitic acid, palmitoleic acid, stearic acid, and oleic acid $(26,27,32-34)$. The relative amounts of the phospholipids vary with growth conditions (e.g., carbon source, nutrient availability, temperature, and growth phase) and with genetic variations $(18,26,28,29)$. Although the proportions of the individual phospholipids change, the average charge of the membrane phospholipids remains relatively constant $(29,35)$. Thus, regulatory mechanisms exist in $S$. cerevisiae to compensate for changes in the levels of phospholipids of one charge by coordinating parallel changes in the levels of phospholipids of the opposite charge.

The pathways for the synthesis of major phospholipids in $S$. cerevisiae are presented in Figure 2. The structural genes and enzymes involved in the pathways have been confirmed by the analysis of gene mutations and the biochemical characterization of purified enzymes $(12,15,28,36,37)$. The synthesis of membrane phospholipids begins with the phospholipid PA, which is produced from glycerol-3-phosphate or dihydroxyacetone phosphate after fatty acyl coenzyme A (CoA)-dependent reactions that are catalyzed by the $S C T 1$ - and GPT2encoded glycerol-3-phosphate acyltransferases and the $S L C 1$ - and $A L E 1$-encoded lysophospholipid acyltransferases (38-44). In the de novo pathways, all membrane phospholipids are synthesized from PA via the liponucleotide intermediate CDP-DAG. The CDS1-encoded CDP-DAG synthase catalyzes the formation of CDP-DAG from PA using the nucleotide CTP for the donation of the CMP moiety $(45,46)$. CDP-DAG may then donate its phosphatidyl moiety to inositol to form PI (47) in the reaction catalyzed by the PIS1-encoded PI synthase $(48,49)$. The inositol used in this reaction is derived from glucose-6-phosphate via the reactions catalyzed by the INO1-encoded inositol-3-phosphate synthase $(50,51)$ and the INM1-encoded inositol-3-phosphate phosphatase $(52)$.

Alternatively, the inositol used in the reaction may be obtained exogenously via the ITR 1and ITR2-encoded inositol permeases (53). CDP-DAG may also donate its phosphatidyl moiety to glycerol-3-phosphate to form phosphatidylglycerophosphate (PGP) in the reaction catalyzed by the $P G S 1$-encoded PGP synthase $(54,55)$. PGP is then dephosphorylated to PG by the GEP4-encoded PGP phosphatase (56). The CRD1-encoded CL synthase (57-59) catalyzes the reaction between PG and another molecule of CDP-DAG to generate CL. The final enzyme that utilizes CDP-DAG in the pathway is the CHO1-encoded PS synthase (6062), which catalyzes the formation of PS by displacement of CMP from CDP-DAG with Ser (63). PS is then decarboxylated to PE by the PSD1- $(64,65)$ and PSD2-encoded (66) PS decarboxylase enzymes. PE is then converted to PC by the three-step $S$-adenosyl methionine (AdoMet)-dependent methylation reactions (67), whereby the first methylation reaction is catalyzed by the $\mathrm{CHO}$-encoded PE methyltransferase $(68,69)$ and the last two methylation reactions are catalyzed by the $O P I 3$-encoded phospholipid methyltransferase $(68,70)$. 
PE and PC are also synthesized from exogenously supplied ethanolamine and choline [via the HNM1-encoded choline permease $(71,72)]$, respectively, by way of the CDPethanolamine and CDP-choline branches of the Kennedy pathway (Figure 2). The EKI1encoded ethanolamine kinase (73) and the CKI1-encoded choline kinase (74) enzymes phosphorylate ethanolamine and choline with ATP to form phosphoethanolamine and phosphocholine, respectively. These intermediates are then activated with CTP to form CDP-ethanolamine and CDP-choline, respectively, by the ECT1-encoded phosphoethanolamine cytidylyltransferase (75) and the PCT1-encoded phosphocholine cytidylyltransferase (76). Finally, CDP-ethanolamine and CDP-choline react with DAG to form PE and PC, respectively, in the reactions catalyzed by the EPT1-encoded ethanolamine phosphotransferase $(77,78)$ and the $C P T 1$-encoded choline phosphotransferase $(79,80)$.

The CTP required for the synthesis of CDP-DAG, CDP-ethanolamine, and CDP-choline is derived from UTP by the URA7-(81) and URA8-encoded (82) CTP synthetase enzymes. The DAG used for the synthesis of PE and PC via the Kennedy pathway is derived from PA by the $P A H 1$-encoded PA phosphatase (24). ${ }^{1}$ The DAG generated in the PA phosphatase reaction may be converted back to PA by the $D G K 1$-encoded DAG kinase ${ }^{2}(83,84)$ or used for the synthesis of the neutral lipid TAG (24) by acyltransferase enzymes encoded by $D G A 1$ and $L R O 1$ (85). The ARE1- and ARE2-encoded acyltransferase enzymes, which are primarily responsible for the synthesis of ergosterol esters, can also acylate DAG to form TAG (85).

The CDP-DAG pathway is primarily used for the synthesis of PE and PC when cells are grown in the absence of ethanolamine and choline (12, 27, 28, 86). Yet, the Kennedy pathway contributes to the synthesis of $\mathrm{PE}$ and $\mathrm{PC}$ when these precursors are not supplemented $(37,73,87)$. For example, the PC synthesized by way of the CDP-DAG pathway is constantly hydrolyzed to choline and PA $(87,88)$ by the $S P O 14$-encoded $(89,90)$ phospholipase D. The choline is incorporated back into $\mathrm{PC}$ via the CDP-choline branch of the Kennedy pathway, and the PA is converted to other phospholipids via the intermediates CDP-DAG and DAG $(12,15,87)$. Choline may also be derived from PC through the phospholipase B and glycerophosphocholine phosphodiesterase activities encoded by NTE1 (91) and GDE1 (92), respectively (93-95). Analysis of mutants indicates that the physiological roles of PC synthesized by the two pathways may be different $(93,96,97)$.

The Kennedy pathway plays a critical role in the synthesis of PE and PC when the enzymes in the CDP-DAG pathway are defective $(12,36)$. For example, the cho 2 opi3 mutant deficient in the three-step methylation of $\mathrm{PE}$ requires choline supplementation for growth and synthesizes PC via the CDP-choline branch of the Kennedy pathway $(68-70,98)$. The cho1 and psd1 psd 2 mutants deficient in the synthesis of PS $(99,100)$ and PE $(66,101)$, respectively, can synthesize $\mathrm{PC}$ if they are supplemented with ethanolamine or choline. The ethanolamine is incorporated into PE via the CDP-ethanolamine branch of the Kennedy pathway, and the PE is subsequently methylated to form PC. Mutants defective in the CDPDAG pathway can also synthesize PE or PC when they are supplemented with lysoPE, lysoPC, or PC with short acyl chains. LysoPE and lysoPC transported into the cell are acylated to PE and PC, respectively, by the $A L E 1$-encoded lysophospholipid acyltransferase, which also utilizes lysoPA as a substrate $(41,42,102,103)$. Short acyl chain

\footnotetext{
${ }^{1}$ PA phosphatase is distinguished in catalytic and physiological functions from the DPP1- and LPP1-encoded lipid phosphate phosphatase enzymes that dephosphorylate a broad spectrum of substrates (including PA, lysoPA, DAG pyrophosphate, sphingoid base phosphates, and isoprenoid phosphates) by a distinct catalytic mechanism that does not require divalent cations $(16,31,213$, 214). The DPP1- and LPP1-encoded lipid phosphate phosphatase enzymes are associated with the vacuole and Golgi membranes, respectively, and are thought to be involved with lipid signaling $(16,31)$.

2 The yeast DAG kinase differs from the enzyme in animals, plants, worms, flies, and bacteria in that the yeast enzyme utilizes CTP instead of ATP as the phosphate donor in the reaction $(83,84)$.
} 
PC, which is not incorporated directly into membranes, is remodeled with 16- and 18-carbon acyl chains (104) by the activities of phospholipase B and lysophospholipid acyltransferase $(94,95,105)$. The Kennedy pathway mutants (i.e., ckil eki1 and cpt 1 eptI) defective in both the CDP-choline and CDP-ethanolamine branches can synthesize PC only by the CDP-DAG pathway $(73,106,107)$. However, unlike the CDP-DAG pathway mutants $(66,68-70,98-$ 101), the Kennedy pathway mutants do not exhibit any auxotrophic requirements and have an essentially normal complement of phospholipids $(73,107)$.

\section{GENETIC AND BIOCHEMICAL MECHANISMS THAT CONTROL PHOSPHOLIPID SYNTHESIS}

The synthesis of phospholipids is regulated by controlling the expression of enzymes and/or by modulating the catalytic activities. The expression of phospholipid synthesis genes is controlled by multiple factors, including carbon source, nutrient availability, growth stage, $\mathrm{pH}$, and temperature $(12,13,18,20,95,108,109)$. The mechanisms responsible for the regulation of gene expression include a number of cis-and trans-acting elements $(14,18$, $20)$. Of these, the inositol-responsive cis-acting element $\left(\mathrm{UAS}_{\mathrm{INO}}\right)$ and the corresponding trans-acting factors (Ino2p, Ino4p, Opi1p) have been well characterized for transcriptional regulation of phospholipid synthesis genes and are discussed here.

Genes encoding enzymes in the CDP-DAG (e.g., CDS1, CHO1, PSD1, CHO2, and OPI3) and Kennedy (e.g., EKI1, EPT1, CKI1, CPT1) pathways, and in the synthesis of PI (e.g., INOI), as well as the genes encoding the inositol (ITRI) and choline/ethanolamine (HNMI) permeases are coordinately regulated through a $\mathrm{UAS}_{\mathrm{INO}}$ element in the promoter. The $\mathrm{UAS}_{\text {INO }}$ element binds the Ino2p-Ino4p heterodimer that activates transcription, and transcriptional activation is repressed when Opilp binds to Ino2p $(14,18)$. Thus, the opi1 mutant exhibits derepressed levels of the $\mathrm{UAS}_{\mathrm{INO}}$-containing genes, whereas the ino 2 and ino4 mutants exhibit repressed levels of $\mathrm{UAS}_{\mathrm{INO}}$-containing genes $(28,29,36,37)$. Because of the constitutive derepression of INO1 expression, opi1 mutants produce excessive amounts of inositol and excrete it into the growth medium, but ino 2 and ino4 mutants lacking transcriptional activation of INO1 are auxotrophic for inositol (28, 29, 36, 37). These inositol-related phenotypes are commonly used as indicators of the misregulation of $\mathrm{UAS}_{\mathrm{INO}}$-containing genes $(36,37)$.

The repressor function of Opi1p is controlled by its cellular location $(14,18,110)$. Opi1p, which lacks a membrane-spanning domain (111), is found at the nuclear/endoplasmic reticulum (ER) membrane and within the nucleus $(110,112,113)$. It associates with the membrane through interaction with the integral membrane protein Scs2p, and its membrane association is stabilized by interaction with PA $(110,112)$. The involvement of Scs $2 p$ in the Opilp-mediated regulation of phospholipid synthesis is evident because the $\operatorname{scs} 2$ mutant is auxotrophic for inositol, a phenotype shown by the constitutive repression of INO1 (114116). This observation predicts a nuclear localization of Opi1p for its increased repressor function. Interestingly, the $s c s 2$ mutant also shows an increase in PC synthesis via the Kennedy pathway, and a block in PC synthesis (e.g., cki1 scs2) restores normal INO1 expression (116). As discussed above, $\mathrm{PC}$ synthesis via the Kennedy pathway consumes PA via DAG, and a block in the Kennedy pathway should result in PA accumulation. Thus, the suppression of inositol auxotrophy for the scs 2 mutant might be explained by a change in the localization of Opilp to the nuclear/ER membrane through interaction with PA.

Genetic and biochemical data indicate that PA has a major effect on the localization and function of Opilp (14). According to a recent model (Figure 3) $(14,18,110)$, Opi1p is tethered to the nuclear/ER membrane via interactions with Scs2p and PA. When PA levels are reduced, Opilp is released from the membrane and enters into the nucleus, where it 
attenuates transcription by binding to Ino2p. That PA governs the Opi1p-mediated regulation of $\mathrm{UAS}_{\mathrm{INO}}$-containing genes is supported by the analyses of mutants defective in the CDP-DAG and Kennedy pathways (14). For example, mutants (e.g., cho1, psd1, cho2, and opi3) defective in any step of the CDP-DAG pathway exhibit increased levels of PA and excrete inositol owing to constitutive derepression of INO1 expression $(36,37)$. However, the inositol excretion phenotype can be alleviated when the mutants are supplemented with a water-soluble precursor (e.g., ethanolamine and choline) that channels PA to phospholipid synthesis via the Kennedy pathway $(12,37)$. In combination with a mutation in the SEC14 encoded PI/PC transfer protein, CDP-choline pathway mutants (e.g., cki1 sec14, pct1 sec14, and cpt 1 sec14) excrete in-ositol and choline, and this phenotype is dependent on the excess productions of PA and choline by the SPO14-encoded phospholipase D-mediated turnover of PC $(87,117)$.

The level of PA can be directly affected by the activities of lysoPA acyltransferase, CDPDAG synthase, PA phosphatase, DAG kinase, and phospholipase D. Of these enzymes, PA phosphatase and DAG kinase have emerged as key regulators of PA in the expression of $\mathrm{UAS}_{\mathrm{INO}}$-containing genes. Cells lacking the $\mathrm{PAH1}$-encoded PA phosphatase activity contain an elevated level of PA and exhibit the derepression of $\mathrm{UAS}_{\mathrm{INO}}$-containing phospholipid synthesis genes (e.g., INO1, OPI3, and INO2) $(24,108,118)$. By contrast, the overexpression of PA phosphatase activity causes the loss of PA, the repression of INO1 expression, and inositol auxotrophy (119). The lack of PA phosphatase activity also causes the abnormal expansion of the nuclear/ER membrane $(108,118)$, underscoring the importance of phospholipid synthesis to organelle synthesis and structure. The DGK1encoded DAG kinase counteracts the role that the $P A H 1$-encoded PA phosphatase plays in controlling PA content and the transcriptional regulation of $\mathrm{UAS}_{\mathrm{INO}}$-containing genes (83, 84). The overexpression of DAG kinase causes an increase in PA content, the derepression of $\mathrm{UAS}_{\mathrm{INO}}$-containing genes, and the abnormal nuclear/ER membrane expansion (83) as in those shown in the pah1 mutant $(108,118)$. Yet, the overexpression of DAG kinase activity complements the inositol auxotrophy caused by the overexpression of PA phosphatase activity (83), whereas the loss of DAG kinase activity (e.g., in the $d g k 1$ mutation) complements the phenotypes caused by the loss of PA phosphatase activity (e.g., in the pah1 mutation) $(83,84)$.

The PA-mediated regulation of $\mathrm{UAS}_{\mathrm{INO}}$-containing genes is triggered by the availability of inositol, zinc, and nitrogen as well as the growth stage $(12,18,20)$. For example, the supplementation of the essential nutrient zinc to the growth medium activates the expression of UAS $\mathrm{UNO}_{\mathrm{INO}}$-containing genes $(20,120)$. By contrast, inositol supplementation represses the gene expression $(12,14,18)$, and the repressive effect is enhanced by ethanolamine or choline supplementation (12). The $\mathrm{UAS}_{\mathrm{INO}}$-containing genes are maximally expressed in the exponential phase of growth, whereas they are repressed in the stationary phase of growth $(12,14,18)$. In many cases, it is the biochemical regulation of a phospholipid synthesis enzyme that ultimately controls the cellular level of PA. The following examples typify this theme of regulation.

\section{Inositol-Mediated Regulation}

Inositol is an essential phospholipid precursor in yeast cells because it is incorporated, through the major phospholipid PI, into polyphosphoinositides (30), sphingolipids (121), and glycosylphosphatidylinositol anchors (122). The syntheses and physiological roles of these inositol-containing membrane components are covered in recent review articles (30, $121,122)$. As discussed above, inositol is synthesized in the cell, but when supplemented to the growth medium, it affects the de novo synthesis of inositol and membrane phospholipid synthesis $(12,13,18,28,36)$. Inositol supplementation causes an increase in the synthesis of PI by a mechanism that involves increased substrate availability for PI synthase (123). In 
addition, inositol directly inhibits the activity of PS synthase, which favors the utilization of their common substrate CDP-DAG for PI synthesis (123). This biochemical regulation draws upon the PA content through CDP-DAG and causes the translocation of Opilp into the nucleus for repression of $\mathrm{UAS}_{\mathrm{INO}}$-containing genes $(14,110)$. Overall, the repression of the $\mathrm{UAS}_{\mathrm{INO}}$-containing genes leads to a decrease in the synthesis of enzymes used in both the CDP-DAG and Kennedy pathways, and this repression causes changes, including an increase in PI and decreases in PA, PS, and PC, in the phospholipid composition $(12,123)$. Changes in membrane phospholipid composition are also the result of phospholipid turnover that is mediated by enzymes, such as the NTE1-encoded phospholipase B (94, 124-126). In fact, the activity of this phospholipase $\mathrm{B}$, which does not have a direct effect on the metabolism of PA, attenuates the repressor function of Opi1p when PC synthesis via the Kennedy pathway is stimulated by choline supplementation at an elevated temperature (126). Inositol supplementation also has global effects on cell physiology, including the unfolded protein response and cell wall integrity pathways $(13,127,128)$.

\section{Zinc-Mediated Regulation}

The synthesis of phospholipids is coordinately regulated with the expression of zinc transporters that control zinc homeostasis $(20,129)$. Cells grown in zinc-depleted medium exhibit the induced expression of zinc transporters (e.g., Zrt1p, Zrt2p, Fet4p, and Zrt3p) to maintain the cytoplasmic levels of zinc $(130,131)$. At the same time, zinc depletion causes alterations in membrane phospholipid composition that are brought about by changes in the expression of phospholipid synthesis enzyme activities (20,120,132-134). The regulation of $\mathrm{UAS}_{\mathrm{INO}}$-containing genes by zinc involves the control of PA content through the activation of $P I S 1$-encoded PI synthase and $P A H 1$-encoded PA phosphatase activities. This regulation, which occurs in the absence of inositol supplementation, is mediated by the zincsensing and zinc-inducible transcriptional activator Zap1p and the zinc-responsive cis-acting

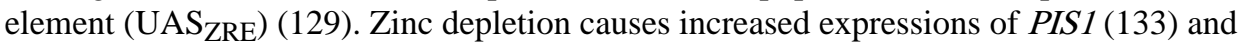
$P A H 1$ (A. Soto-Cardalda \& G.M. Carman, unpublished data) by the interaction of Zap1p with a $U_{A S} S_{Z R E}$ in the promoter. The net results are the Opi1p-mediated repression of $\mathrm{UAS}_{\mathrm{INO}}$-containing genes and a decrease in the activities of the CDP-DAG pathway enzymes (120). The major effects of zinc depletion on phospholipid composition include an increase in PI and a decrease in PE (120). Although enzyme activities in the CDP-DAG pathway are reduced by zinc depletion, the amount of PC is not significantly affected (120). Maintenance of a normal PC content is attributed to the Zap1p-mediated inductions of choline kinase and ethanolamine kinase for PC synthesis via the Kennedy pathway (132, 135). Like $P I S 1$ and $P A H 1$, the $C K I 1$ and $E K I 1$ genes contain a $\mathrm{UAS}_{\mathrm{ZRE}}$ in their promoters that interacts with Zap1p for gene activation $(132,135)$. Any effect that Opi1p would have on the expressions of $C K I 1$ and EKII (because they contain UAS $_{\text {INO }}$ elements) is overcome by the derepression by Zap1p $(132,135)$.

The fact that the zinc transporters are localized to cellular membranes raises the question as to whether zinc-mediated alterations in phospholipid composition might regulate transporter function. Several reports have shown that PE plays a major role in transporter function. For example, PE is required for amino acid transporter function in $S$. cerevisiae $(136,137)$, and its content in Escherichia coli is required for function of the $a$-aminobutyric acid (138), lactose $(139,140)$, and phenylalanine (141) transporters. The availability of mutants (e.g., eki1, psd1, psd2) defective in PE synthesis should facilitate studies to address the importance of changing PE content for the zinc transport function in S. cerevisiae.

\section{CTP-Mediated Regulation}

In $S$. cerevisiae, the nucleotide CTP plays a critical role in phospholipid synthesis as the direct precursor of the high-energy intermediates CDP-DAG, CDP-choline, and CDP- 
ethanolamine that are used in the CDP-DAG and Kennedy pathways (Figure 2) (17). It is also used as the phosphate donor for the synthesis of PA by the DAG kinase (84). CTP synthetase $(81,82)$, which produces CTP, is allosterically inhibited by the product $(142$, 143), and this regulation ultimately determines the intracellular concentration of CTP (142, 144). CTP inhibits the CTP synthetase activity by increasing the positive cooperativity of the enzyme for UTP and by simultaneously decreasing the enzyme's affinity for UTP (142, 143). However, CTP synthetases containing an E161K mutation are less sensitive to CTP product inhibition (145), and cells expressing the mutant enzymes exhibit a 6- to 15-fold increase in their CTP level (145). They also show alterations in the synthesis of membrane phospholipids, which include a decrease in the synthesis of PS and an increase in the synthesis of PC, PE, and PA (145). The decrease in the synthesis of PS results from direct inhibition of PS synthase activity by CTP (144), and this inhibition favors the synthesis of phospholipids by the Kennedy pathway. The increase in PC synthesis is ascribed to a higher utilization of the CDP-choline branch of the Kennedy pathway owing to the stimulation of phosphocholine cytidylyltransferase activity $(144,145)$ by the increased substrate availability of CTP $(144,146)$. Likewise, the increase in PE synthesis could be attributed to stimulation of phosphoethanolamine cytidylyltransferase activity. The increase in PA content may result from the stimulation of DAG kinase activity by increased availability of its substrate CTP (84). The cells expressing the E161K mutant enzyme excrete inositol (145), a characteristic phenotype that typifies the misregulation of UAS INO-containing phospholipid synthesis genes when cells accumulate an excess of PA (14). It is unclear whether UAS $\mathrm{INO}_{\mathrm{INO}}$-containing genes in the CDP-DAG and Kennedy pathways are derepressed in CTP overproducing cells, but the overriding regulation that governs the utilization of the two pathways appears to be biochemical in nature.

\section{CDP-Diacylglycerol-Mediated Regulation}

The PA phosphatase and DAG kinase enzymes are differentially regulated by CDP-DAG. This liponucleotide intermediate stimulates PA phosphatase activity (147) but inhibits DAG kinase activity (84). However, the opposing regulations of PA metabolic enzymes favor a decrease in PA content and the Opilp-mediated repression of UAS $\mathrm{INO}_{\mathrm{INO}}$-containing genes. One of the $\mathrm{UAS}_{\mathrm{INO}}$-containing genes that are repressed by Opilp is $C D S 1$ (148), which codes for CDP-DAG synthase (46). Thus, the regulation of its own expression provides a mechanism for controlling the synthesis of CDP-DAG from PA and the CDP-DAGdependent synthesis of phospholipids. This regulation is supported by the genetic evidence that a conditional $c d s 1$ mutant defective in CDP-DAG synthase activity exhibits an elevated PA content and the derepression of $\mathrm{UAS}_{\text {INO-containing genes }(149,150) \text {. The increased }}$ DAG levels caused by the CDP-DAG-mediated regulation of PA phosphatase and DAG kinase activities would be channeled to phospholipids via the Kennedy pathway or to the neutral lipid TAG.

\section{S-Adenosyl-L-Homocysteine-Mediated Regulation}

$S$-Adenosyl-L-homocysteine (AdoHcy) is a product of the AdoMet-dependent methylation reactions that are catalyzed by the $\mathrm{CHO}$-encoded PE methyltransferase and $O P I 3$-encoded phospholipid methyltransferase in the CDP-DAG pathway (Figure 2). Ado-Hcy, which is removed by the $S A H 1$-encoded AdoHcy hydrolase (23), is a competitive inhibitor of the methyltransferase enzymes (151). Thus, downregulation of the AdoHcy hydrolase causes the accumulation of AdoHcy and the inhibition of PC synthesis, which leads to an increase

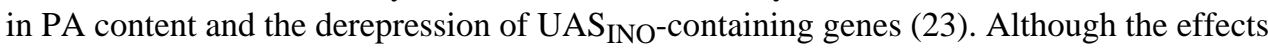
of AdoHcy on phospholipid composition have not been addressed, its accumulation causes an increase in TAG synthesis and lipid droplet content (23). 


\section{REGULATION OF PHOSPHOLIPID SYNTHESIS BY PHOSPHORYLATION}

Phosphorylation is a major covalent posttranslational modification by which the activity of an enzyme or a transcription factor is regulated (152-157). Enzyme phosphorylation can affect catalytic activity and/or subcellular localization. Phosphorylation of a regulatory protein can control its localization, stability, and interaction with DNA or other proteins. Data indicate that phospholipid synthesis in yeast is regulated by phosphorylation at Ser and Thr residues. The protein kinases known to regulate the function of catalytic and regulatory proteins in phospholipid synthesis include protein kinase $\mathrm{A}$, protein kinase $\mathrm{C}$, casein kinase II, and cyclin-dependent kinase. Protein kinase A is the principal mediator of signals transmitted through the $R A S / \mathrm{cAMP}$ pathway $(158,159)$. Its activity is required for proper regulation of growth, progression through the cell cycle, and development in response to various nutrients $(158,159)$. Protein kinase A consists of two catalytic subunits (encoded by $T P K 1, T P K 2$, and $T P K 3$ ) and two regulatory subunits (encoded by $B C Y 1$ ). Elevated cAMP levels, which are controlled by adenylate cyclase (encoded by $C Y R I$ ) via the $R A S$-cAMP pathway, promote dissociation of the regulatory subunits from the catalytic subunits and thus allow the catalytic subunits to phosphorylate a variety of substrates $(158,159)$. Protein kinase C (encoded by $P K C 1$ ) is essential for the progression of the cell cycle (160) and plays a role in cell wall formation (161). Casein kinase II is essential for cell viability (162-164), and the enzyme is composed of two catalytic (encoded by $C K A 1$ and $C K A 2$ ) and two regulatory ( $C K B 1$ and $C K B 2)$ subunits (165-168). The $C D C 28$ ( $C D K 1)$-encoded cyclindependent kinase is a master regulator of cell-cycle transitions whose activity is governed by interactions with various G1 and B-type cyclins (169). Phospholipid synthesis enzymes, which are regulated by phosphorylation, include PS synthase, CTP synthetase, choline kinase, and PA phosphatase. The transcriptional repressor Opilp is also regulated by phosphorylation.

\section{Opi1p Phosphorylation}

The Opilp repressor plays a negative regulatory role in the expression of $\mathrm{UAS}_{\mathrm{INO}^{-}}$ containing genes involved in the synthesis of membrane phospholipids $(111,170)$. In vivo labeling studies have shown that Opilp is phosphorylated at multiple Ser residues (171, 172). In vitro studies indicate that protein kinase $A$ (172), protein kinase $C$ (171), and casein kinase II (173) play major roles in the phosphorylation. The major sites of Opilp phosphorylation include $\mathrm{Ser}^{10}$ (for casein kinase II), $\operatorname{Ser}^{26}$ (for protein kinase C), and $\mathrm{Ser}^{31}$ and $\operatorname{Ser}^{251}$ (for protein kinase A) (Figure 4) (171-173). The analysis of opi1 cells expressing phosphorylation-deficient (e.g., Ser $\rightarrow$ Ala mutations) forms of Opilp indicates that protein kinases $\mathrm{A}$ and $\mathrm{C}$ are responsible for $\sim 50 \%$ of the total phosphorylation that occurs in vivo $(171,172)$. By contrast, phosphorylation by casein kinase II does not have a major effect on the extent of Opi1p phosphorylation in vivo (173). In vitro the mutation (S26A) in the protein kinase $\mathrm{C}$ target site reduces the phosphorylation of Opilp by protein kinase $\mathrm{A}$. Likewise, the mutations (S31A and S251A) in protein kinase A target sites reduce the phosphorylation by protein kinase C. By contrast, the mutation (S10A) in the casein kinase II target site does not affect the in vitro phosphorylation by either protein kinase A or protein kinase C. Furthermore, the mutations in the protein kinase $\mathrm{A}$ or protein kinase $\mathrm{C}$ target sites do not affect the phosphorylation of Opilp by casein kinase II. These results indicate that phosphorylation by protein kinase A stimulates phosphorylation by protein kinase $\mathrm{C}$ and vice versa and that the phosphorylations by these kinases are independent of the phosphorylation by casein kinase II. The hierarchical phosphorylations by protein kinases A and $\mathrm{C}$ provide an explanation as to why the protein kinase $\mathrm{A}$ and protein kinase $\mathrm{C}$ phosphorylation site mutations affect the overall phosphorylation state of Opilp in vivo and as to why the casein kinase II site mutation does not have a major effect on the overall phosphorylation state of the protein. 
The phosphorylation of Opi1p at $\mathrm{Ser}^{10}, \mathrm{Ser}^{31}$, and $\mathrm{Ser}^{251}$ stimulates its repressor function (172), whereas phosphorylation at $\operatorname{Ser}^{26}$ attenuates its repressor function (171). The regulation of Opilp function via phosphorylation by protein kinases A and $\mathrm{C}$ occurs in cells grown in the absence and presence of inositol $(171,172)$, whereas the regulation via phosphorylation by casein kinase II occurs only when cells are grown in the absence of inositol (173). Opi1p possesses binding domains for PA, Scs2p, Ino2p, and Sin3p (Figure 4) $(110,112,174,175)$, which affect its localization and function. Whether the phosphorylation of Opi1p by protein kinases $\mathrm{A}$ and $\mathrm{C}$, as well as by casein kinase II, influences the interaction of Opilp with its binding partners warrants further investigation.

\section{Phosphatidylserine Synthase Phosphorylation}

The $C H O 1$-encoded PS synthase is one of the most highly regulated enzymes for the synthesis of phospholipids in $S$. cerevisiae $(12,15,176)$. This ER-associated enzyme catalyzes the formation of PS in the $\mathrm{Mn}^{2+}$-dependent sequential reaction that displaces CMP from CDP-DAG with Ser $(60-62,177,178)$. PS synthase possesses a CDP-alcohol phosphotransferase domain that is shared by other phospholipid synthesis enzymes (e.g., PI synthase and PGP synthase) catalyzing similar types of reactions (Figure 4) (179). PS synthase exists in two forms that differ in the electrophoretic mobility ( $30 \mathrm{kDa}$ and $27 \mathrm{kDa}$ ). The 30-kDa form of PS synthase is produced from the $27-\mathrm{kDa}$ form by protein kinase Amediated phosphorylation at $\mathrm{Ser}^{46}$ and $\mathrm{Ser}^{47}$ (180). The abundance of the two forms is dependent on the cell growth phase but not on the regulated expression of $\mathrm{CHO}$ by inositol supplementation or respiratory deficiency (180). The 30-kDa and 27-kDa forms are present in exponential phase cells, whereas the $27-\mathrm{kDa}$ form is primarily present in the stationary phase cells.

Phosphorylation of PS synthase by protein kinase A inhibits its catalytic activity (181), and the inhibitory effect of phosphorylation is abolished by S46A/S47A mutations (180). The expression of phosphorylation-deficient PS synthase shows that its cellular level is about twofold lower than that of the wild-type enzyme, resulting in a reduction of the total PS synthase activity. The lower PS synthase activity in cells expressing the S46A/S47A mutant enzyme correlates with a reduction in PS relative to PI and a decrease in PS synthesis in vivo (180). These observations support the conclusion that protein kinase A phosphorylation has dual roles in the regulation of PS synthase. On the one hand, phosphorylation inhibits PS synthase activity, but on the other hand, it stabilizes the abundance of the enzyme. The dual regulation of PS synthase results in a net increase in cellular PS synthase activity, which must be important to the optimal function of PS synthase during the exponential phase of cell growth (182). When the need for phospholipid synthesis is reduced in the stationary phase (183), the total amount of PS synthase is reduced because of a lack of phosphorylation and, at the same time, because of reduced gene repression (184).

\section{CTP Synthetase Phosphorylation}

CTP synthetase that is encoded by $U R A 7$ and $U R A 8$ is an essential cytosolic enzyme that catalyzes a committed step in the synthesis of membrane phospholipids in S. cerevisiae (81, 82). The enzyme contains conserved CTP synthetase and glutamine amide transfer domains that are involved in catalysis (Figure 4) (17). CTP synthetase catalyzes a complex set of reactions, including the ATP-dependent transfer of the amide nitrogen from glutamine (i.e., the glutaminase reaction) to the C-4 position of UTP to generate CTP $(185,186)$. GTP stimulates the glutaminase reaction by accelerating the formation of a covalent glutaminyl enzyme intermediate $(185,186)$. The $U R A 7$-encoded CTP synthetase is phosphorylated by protein kinase $\mathrm{A}$ and by protein kinase $\mathrm{C}(187,188)$. The phosphorylations by these protein kinases stimulate CTP synthetase activity by two- to threefold $(187,188)$. Kinetic analyses show that the mechanisms for stimulation of CTP synthetase activity by these protein 
kinases are the same $(187,188)$. Phosphorylated CTP synthetase shows an increase in the $V_{\text {max }}$ with respect to the substrates UTP and ATP, a decrease in the $K_{m}$ value for ATP, and a decrease in the positive cooperativity of the enzyme for ATP $(187,188)$. Moreover, the phosphorylation of CTP synthetase by protein kinases $\mathrm{A}$ and $\mathrm{C}$ attenuates the regulation of its activity by CTP product inhibition $(187,188)$.

The effects of phosphorylation on the regulation of CTP synthetase activity involve the oligomerization of the enzyme $(142,189)$. CTP synthetase exists as a dimer in the absence of ATP and UTP, but the enzyme forms a tetramer in the presence of saturating concentrations of the substrates $(142,189)$. The kinetics of enzyme tetramerization correlates with the kinetics of enzyme activity. The product CTP does not inhibit the ATP/ UTP-dependent tetramerization of the enzyme $(142,189)$. Phosphorylation of native CTP synthetase with protein kinases A and C facilitates the nucleotide-dependent tetramerization, whereas dephosphorylation of native CTP synthetase prevents its nucleotide-dependent tetramerization (189). This regulation correlates with the inactivation of CTP synthetase activity (189). The rephosphorylation of the enzyme with protein kinases A and C results in a partial restoration of the nucleotide-dependent tetramerization of the enzyme, and this correlates with the partial restoration of CTP synthetase activity (189).

Ser ${ }^{424}$ is a target site for both protein kinase A and protein kinase C $(190,191)$. The phosphorylation of this site is required to maintain optimum CTP synthetase activity in vivo $(190,191)$. Protein kinase C also phosphorylates the enzyme at $\mathrm{Ser}^{36}, \mathrm{Ser}^{330}, \mathrm{Ser}^{354}$, and $\mathrm{Ser}^{454}$ (192). Biochemical and physiological analyses of Ser $\rightarrow$ Ala mutations have shown that phosphorylations at the Ser residues, except $\mathrm{Ser}^{330}$, result in the stimulation of CTP synthetase activity $(191,192)$. The phosphorylation at $\operatorname{Ser}^{330}$ results in the inhibition of the enzyme activity (192). Moreover, in vivo studies using these mutants have shown that the regulatory effects of the phosphorylations at specific sites have an impact on the pathways by which membrane phospholipids are synthesized. Phosphorylations at $\mathrm{Ser}^{36}, \mathrm{Ser}^{354}$, and $\mathrm{Ser}^{454}$ correlate with an increase in PC synthesis via the Kennedy pathway $(191,192)$. In contrast, phosphorylation at $\mathrm{Ser}^{330}$ correlates with a decrease in the utilization of the Kennedy pathway (192).

\section{Choline Kinase Phosphorylation}

The $C K I 1$-encoded choline kinase $(74,193)$ is a cytosolic enzyme that plays a regulatory role in the synthesis of PC via the CDP-choline branch of the Kennedy pathway (12, 86, 194). The enzyme catalyzes the phosphorylation of choline with ATP to form phosphocholine and ADP (195). Choline kinase contains conserved phosphotransferase and choline kinase motifs (196-198) that are involved in its catalytic function (Figure 4) (198200). Choline kinase is phosphorylated at multiple Ser residues in vivo, and the phosphorylations at some of these sites are mediated by protein kinases A (201) and C (202).

Protein kinase A phosphorylates choline kinase at $\mathrm{Ser}^{30}$ and $\mathrm{Ser}^{85}$, with the former site having the major effect on enzyme regulation (203). Protein kinase C phosphorylates $\operatorname{Ser}^{25}$ as well as $\operatorname{Ser}^{30}$ (202). Because protein kinases A and C phosphorylate $\mathrm{Ser}^{30}$, phosphorylation of choline kinase by one protein kinase reduces phosphorylation of the enzyme at the same site by the other protein kinase (202). Phosphorylation of choline kinase at $\mathrm{Se}^{25}$ by protein kinase C does not affect phosphorylation by protein kinase A (202). Analysis of ckil eki1 cells expressing S25A and S30A mutant forms of choline kinase indicates that the phosphorylations at $\mathrm{Ser}^{25}$ and $\mathrm{Ser}^{30}$ by protein kinases A and C stimulate activity ( twofold) and that these phosphorylations cause the concomitant increase in PC synthesis via the Kennedy pathway $(202,203)$. 


\section{Phosphatidate Phosphatase Phosphorylation}

The PAH1-encoded PA phosphatase catalyzes the dephosphorylation of PA to yield DAG and $P_{i}(24,204)$. This reaction is specific for $P A$, with a cofactor requirement of $\mathrm{Mg}^{2+}$ ions, and is based on a catalytic motif within a haloacid dehalogenase-like domain of the enzyme (Figure 4) $(16,24,118)$. PA phosphatase activity is associated with the cytosolic and membrane fractions of the cell, and its membrane association is peripheral in nature (24). The regulation of PA phosphatase activity governs the synthesis of TAG, the pathways by which phospholipids are synthesized, PA signaling and transcriptional regulation of

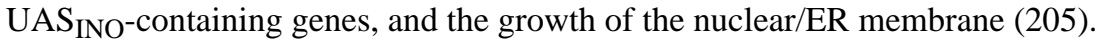

PA phosphatase is phosphorylated at multiple sites in vivo (119). Mass spectrometry analysis of purified PA phosphatase, in combination with immunoblot analysis using an antiphospho Ser/Thr-Pro antibody, has identified 16 sites of phosphorylation (Figure 4); seven of these sites are located within the minimal Ser/Thr-Pro motif that is a target for cell cycle-regulated protein kinases (e.g., Cdc28p and Pho85p) (119). Proteome-wide in vitro phosphorylation analyses have shown that the enzyme is a target for protein kinases, including those encoded by $C D C 28$ (CDK1) (206), PHO85 (207, 208), and DBF2 (209). That PA phosphatase is a target for Cdc28p in vivo is supported by the observations that the electrophoretic mobility of PA phosphatase increases in a temperature-sensitive $c d c 28-4$ mutant defective in cyclin-dependent kinase activity and in a cyclin clb3 clb4 mutant, whereas PA phosphatase electrophoretic mobility decreases when cells enter the mitotic phase of growth (108). Moreover, the slower-migrating PA phosphatase protein is recognized by the antiphospho Ser/Thr-Pro antibody that is specific for cell cycle-regulated phosphoepitopes having the minimal Ser/Thr-Pro motif $(108,210)$, and the seven sites of phosphorylation identified in PA phosphatase have this motif (119).

Phosphorylation of PA phosphatase has an inhibitory effect on the enzyme function in vivo. The Nem1p-Spo7p phosphatase complex is responsible for the dephosphorylation of PA phosphatase, and yeast lacking the phosphatase complex exhibits the phenotypes characteristic of the pah1 mutant (e.g., derepression of phospholipid synthesis genes and aberrant nuclear/ER membrane expansion) defective in PA phosphatase activity (108). In contrast to phosphorylation, the dephosphorylation of PA phosphatase has a stimulatory effect on enzyme function in vivo. Yeast overexpressing PA phosphatase with simultaneous mutations of the seven sites within the Ser/Thr-Pro motif to nonphosphorylatable Ala residues exhibits inositol auxotrophy by exacerbating the Opilp-mediated repression of INO1 expression (presumably owing to reduced PA content) (119). In addition, the phosphorylation-deficient septuple mutant PA phosphatase exhibits elevated (1.8-fold) activity in vitro (119).

Genetic and biochemical data indicate that the association of PA phosphatase with the membrane, where its substrate PA resides, is essential to the enzyme's function in vivo (108, 119). The fact that the Nem1p-Spo7p complex is associated with the nuclear/ER membrane $(108,211)$ indicates that phosphorylated PA phosphatase is recruited to the membrane for its dephosphorylation. In vivo and in vitro studies have shown that the interaction of PA phosphatase with the membrane is dependent on an amphipathic helix found at the Nterminal region of the enzyme (212) and that the interaction through the amphipathic helix is dependent on dephosphorylation by the Nem1p-Spo7p phosphatase complex (212).

\section{CONCLUSIONS}

The regulation of phospholipid synthesis in $S$. cerevisiae is a complex coordinated process that is governed by genetic and biochemical mechanisms, which are interrelated. Gene expression in $S$. cerevisiae is largely controlled by transcriptional regulation that is triggered 
by PA content through biochemical modulation of phospholipid synthesis enzymes. The phospholipid precursors, products, and metabolites, as well as phosphorylation, play important roles in this regulation.

\section{Acknowledgments}

We express our esteem and gratitude to the members of our laboratory, past and present, and to all of our colleagues who have contributed to the understanding of phospholipid biosynthesis in S. cerevisiae. In particular, William Dowhan and Susan A. Henry are acknowledged for their help and encouragement throughout the course of our work on phospholipid biosynthesis in yeast. This work was supported by National Institutes of Health grants GM-28140 and GM-50679.

\section{Glossary}

Phospholipid
PC
PE
PI
PS
PG
CL
Phosphatidate (PA)
CDP-DAG
DAG
UAS INO
Opi1p
Ino2p-Ino4p
heterodimer
Nuclear/endoplasmic
reticulum (ER)
membrane
Zap1p

UAS $_{\text {ZRE }}$

Phosphorylation a membrane component whose structure is based on a glycerol-3-phosphate backbone with fatty acids esterified to positions 1 and 2

phosphatidylcholine

phos-phatidylethanolamine

phosphatidylinositol

phosphatidylserine

phosphatidylglycerol

cardiolipin

a phospholipid precursor that stabilizes the interaction of Opilp with Scs $2 p$ at the nuclear/ER membrane

CDP-diacylglycerol

diacylglycerol

an inositol-responsive cis-acting element found in the promoter of several phospholipid synthesis genes

a repressor protein that interacts with Ino2p to attenuate transcriptional activation by the Ino2p-Ino4p complex

a complex of regulatory proteins that interact with the $\mathrm{UAS}_{\mathrm{INO}}$ element in the promoter to activate transcription

the outer nuclear membrane that is continuous with the endoplasmic reticulum membrane

a transcriptional activator protein that interacts with the $\mathrm{UAS}_{\text {ZRE }}$

a zinc-responsive cis-acting element found in the promoter of some phospholipid synthesis genes

a protein modification that regulates the functions of Opilp and key phospholipid synthesis enzymes

\section{LITERATURE CITED}

1. van Meer G, Voelker DR, Feigenson GW. Membrane lipids: where they are and how they behave. Nat Rev Mol Cell Biol. 2008; 9:112-24. [PubMed: 18216768] 
2. Voelker DR. Genetic and biochemical analysis of nonvesicular lipid traffic. Annu Rev Biochem. 2009; 78:827-56. [PubMed: 19489735]

3. Singer SJ, Nicolson GL. The fluid mosaic model of the structure of membranes. Science. 1972; 175:720-21. [PubMed: 4333397]

4. Exton JH. Phosphatidylcholine breakdown and signal transduction. Biochim Biophys Acta. 1994; 1212:26-42. [PubMed: 8155724]

5. Becker GW, Lester RL. Biosynthesis of phosphoinositol-containing sphingolipids from phosphatidylinositol by a membrane preparation from Saccharomyces cerevisiae. J Bacteriol. 1980; 142:747-54. [PubMed: 6991492]

6. Menon AK, Stevens VL. Phosphatidylethanolamine is the donor of the ethanolamine residue linking a glycosylphosphatidylinositol anchor to protein. J Biol Chem. 1992; 267:15277-80. [PubMed: 1322394]

7. Lester RL, Dickson RC. Sphingolipids with inositolphosphate-containing head groups. Adv Lipid Res. 1993; 26:253-74. [PubMed: 8379454]

8. Fankhauser C, Homans SW, Thomas-Oates JE, McConville MJ, Desponds C, et al. Structures of glycosylphosphatidylinositol membrane anchors from Saccharomyces cerevisiae. J Biol Chem. 1993; 268:26365-74. [PubMed: 8253761]

9. Bishop RE, Gibbons HS, Guina T, Trent MS, Miller SI, Raetz CR. Transfer of palmitate from phospholipids to lipid A in outer membranes of gram-negative bacteria. EMBO J. 2000; 19:507180. [PubMed: 11013210]

10. Ichimura Y, Kirisako T, Takao T, Satomi Y, Shimonishi Y, et al. A ubiquitin-like system mediates protein lipidation. Nature. 2000; 408:488-92. [PubMed: 11100732]

11. Dowhan W, Bogdanov M. Lipid-dependent membrane protein topogenesis. Annu Rev Biochem. 2009; 78:515-40. [PubMed: 19489728]

12. Carman GM, Henry SA. Phospholipid biosynthesis in the yeast Saccharomyces cerevisiae and interrelationship with other metabolic processes. Prog Lipid Res. 1999; 38:361-99. [PubMed: 10793889]

13. Gaspar ML, Aregullin MA, Jesch SA, Nunez LR, Villa-Garcia M, Henry SA. The emergence of yeast lipidomics. Biochim Biophys Acta. 2007; 1771:241-54. [PubMed: 16920401]

14. Carman GM, Henry SA. Phosphatidic acid plays a central role in the transcriptional regulation of glycerophospholipid synthesis in Saccharomyces cerevisiae. J Biol Chem. 2007; 282:37293-97. [PubMed: 17981800]

15. Carman GM, Zeimetz GM. Regulation of phospholipid biosynthesis in the yeast Saccharomyces cerevisiae. J Biol Chem. 1996; 271:13293-96. [PubMed: 8663192]

16. Carman GM, Han GS. Roles of phosphatidate phosphatase enzymes in lipid metabolism. Trends Biochem Sci. 2006; 31:694-99. [PubMed: 17079146]

17. Chang Y-F, Carman GM. CTP synthetase and its role in phospholipid synthesis in the yeast Saccharomyces cerevisiae. Prog Lipid Res. 2008:333-39. [PubMed: 18439916]

18. Chen M, Hancock LC, Lopes JM. Transcriptional regulation of yeast phospholipid biosynthetic genes. Biochim Biophys Acta. 2007; 1771:310-21. [PubMed: 16854618]

19. Carman GM, Kersting MC. Phospholipid synthesis in yeast: regulation by phosphorylation. Biochem Cell Biol. 2004; 82:62-70. [PubMed: 15052328]

20. Carman GM, Han GS. Regulation of phospholipid synthesis in Saccharomyces cerevisiae by zinc depletion. Biochim Biophys Acta. 2007; 1771:322-30. [PubMed: 16807089]

21. Rajakumari S, Grillitsch K, Daum G. Synthesis and turnover of nonpolar lipids in yeast. Prog Lipid Res. 2008; 47:157-71. [PubMed: 18258205]

22. Gaspar ML, Jesch SA, Viswanatha R, Antosh AL, Brown WJ, et al. A block in endoplasmic reticulum-to-Golgi trafficking inhibits phospholipid synthesis and induces neutral lipid accumulation. J Biol Chem. 2008; 283:25735-51. [PubMed: 18614533]

23. Malanovic N, Streith I, Wolinski H, Rechberger G, Kohlwein SD, Tehlivets O. S-adenosyl-Lhomocysteine hydrolase, key enzyme of methylation metabolism, regulates phosphatidylcholine synthesis and triacylglycerol homeostasis in yeast: implications for homocysteine as a risk factor of atherosclerosis. J Biol Chem. 2008; 283:23989-99. [PubMed: 18591246] 
24. Han G-S, Wu W-I, Carman GM. The Saccharomyces cerevisiae lipin homolog is a $\mathrm{Mg}^{2+}$ dependent phosphatidate phosphatase enzyme. J Biol Chem. 2006; 281:9210-18. [PubMed: 16467296]

25. Dickson RC. New insights into sphingolipid metabolism and function in budding yeast. J Lipid Res. 2008; 49:909-21. [PubMed: 18296751]

26. Rattray JB, Schibeci A, Kidby DK. Lipids of yeast. Bacteriol Rev. 1975; 39:197-231. [PubMed: 240350]

27. Henry, SA. Membrane lipids of yeast: biochemical and genetic studies. In: Strathern, JN.; Jones, EW.; Broach, JR., editors. The Molecular Biology of the Yeast Saccharomyces: Metabolism and Gene Expression. Cold Spring Harbor, NY: Cold Spring Harb. Lab; 1982. p. 101-58.

28. Carman GM, Henry SA. Phospholipid biosynthesis in yeast. Annu Rev Biochem. 1989; 58:63569. [PubMed: 2673019]

29. Paltauf, F.; Kohlwein, SD.; Henry, SA. Regulation and compartmentalization of lipid synthesis in yeast. In: Jones, EW.; Pringle, JR.; Broach, JR., editors. The Molecular and Cellular Biology of the Yeast Saccharomyces: Gene Expression. Cold Spring Harbor, NY: Cold Spring Harb. Lab; 1992. p. 415-500.

30. Strahl T, Thorner J. Synthesis and function of membrane phosphoinositides in budding yeast, Saccharomyces cerevisiae. Biochim Biophys Acta. 2007; 1771:353-404. [PubMed: 17382260]

31. Oshiro J, Han G-S, Carman GM. Diacylglycerol pyrophosphate phosphatase in Saccarhomyces cerevisiae. Biochim Biophys Acta. 2003; 1635:1-9. [PubMed: 14642771]

32. Bossie MA, Martin CE. Nutritional regulation of yeast delta- 9 fatty acid desaturase activity. J Bacteriol. 1989; 171:6409-13. [PubMed: 2687232]

33. McDonough VM, Stukey JE, Martin CE. Specificity of unsaturated fatty acid-regulated expression of the Saccharomyces cerevisiae OLE1 gene. J Biol Chem. 1992; 267:5931-36. [PubMed: 1556107]

34. Martin CE, Oh CS, Jiang Y. Regulation of long chain unsaturated fatty acid synthesis in yeast. Biochim Biophys Acta. 2007; 1771:271-85. [PubMed: 16920014]

35. Becker GW, Lester RL. Changes in phospholipids of Saccharomyces cerevisiae associated with inositol-less death. J Biol Chem. 1977; 252:8684-91. [PubMed: 336620]

36. Greenberg ML, Lopes JM. Genetic regulation of phospholipid biosynthesis in Saccharomyces cerevisiae. Microbiol Rev. 1996; 60:1-20. [PubMed: 8852893]

37. Henry SA, Patton-Vogt JL. Genetic regulation of phospholipid metabolism: yeast as a model eukaryote. Prog Nucl Acid Res Mol Biol. 1998; 61:133-79.

38. Athenstaedt K, Daum G. Biosynthesis of phosphatidic acid in lipid particles and endoplasmic reticulum of Saccharomyces cerevisiae. J Bacteriol. 1997; 179:7611-16. [PubMed: 9401016]

39. Athenstaedt K, Weys S, Paltauf F, Daum G. Redundant systems of phosphatidic acid biosynthesis via acylation of glycerol-3-phosphate or dihydroxyacetone phosphate in the yeast Saccharomyces cerevisiae. J Bacteriol. 1999; 181:1458-63. [PubMed: 10049376]

40. Zheng Z, Zou J. The initial step of the glycerolipid pathway: identification of glycerol 3-phosphate/ dihydroxyacetone phosphate dual substrate acyltransferases in Saccharomyces cerevisiae. J Biol Chem. 2001; 276:41710-16. [PubMed: 11544256]

41. Riekhof WR, Wu J, Jones JL, Voelker DR. Identification and characterization of the major lysophosphatidylethanolamine acyltransferase in Saccharomyces cerevisiae. J Biol Chem. 2007; 282:28344-52. [PubMed: 17652094]

42. Jain S, Stanford N, Bhagwat N, Seiler B, Costanzo M, et al. Identification of a novel lysophospholipid acyltransferase in Saccharomyces cerevisiae. J Biol Chem. 2007; 282:30562-69. [PubMed: 17726007]

43. Benghezal M, Roubaty C, Veepuri V, Knudsen J, Conzelmann A. SLC1 and SLC4 encode partially redundant acyl-coenzyme A 1-acylglycerol-3-phosphate $O$-acyltransferases of budding yeast. J Biol Chem. 2007; 282:30845-55. [PubMed: 17675291]

44. Chen Q, Kazachkov M, Zheng Z, Zou J. The yeast acylglycerol acyltransferase LCA1 is a key component of Lands cycle for phosphatidylcholine turnover. FEBS Lett. 2007; 581:5511-16. [PubMed: 17996202] 
45. Carter JR, Kennedy EP. Enzymatic synthesis of cytidine diphosphate diglyceride. J Lipid Res. 1966; 7:678-83. [PubMed: 4291255]

46. Shen H, Heacock PN, Clancey CJ, Dowhan W. The CDS1 gene encoding CDP-diacylglycerol synthase in Saccharomyces cerevisiae is essential for cell growth. J Biol Chem. 1996; 271:789-95. [PubMed: 8557688]

47. Paulus H, Kennedy EP. The enzymatic synthesis of inositol monophosphatide. J Biol Chem. 1960; 235:1303-11. [PubMed: 14431034]

48. Nikawa J, Yamashita S. Molecular cloning of the gene encoding CDP-diacylglycerol-inositol 3phosphatidyl transferase in Saccharomyces cerevisiae. Eur J Biochem. 1984; 143:251-56. [PubMed: 6088233]

49. Nikawa J, Kodaki T, Yamashita S. Primary structure and disruption of the phosphatidylinositol synthase gene of Saccharomyces cerevisiae. J Biol Chem. 1987; 262:4876-81. [PubMed: 3031032]

50. Klig LS, Henry SA. Isolation of the yeast INO1 gene: Located on an autonomously replicating plasmid, the gene is fully regulated. Proc Natl Acad Sci USA. 1984; 81:3816-20. [PubMed: 6374665]

51. Dean-Johnson M, Henry SA. Biosynthesis of inositol in yeast: Primary structure of myo-inositol-1phosphate synthase (EC 5.5.1.4) and functional analysis of its structural gene, the INO1 locus. J Biol Chem. 1989; 264:1274-83. [PubMed: 2642902]

52. Murray M, Greenberg ML. Expression of yeast INM1 encoding inositol monophosphatase is regulated by inositol, carbon source and growth stage and is decreased by lithium and valproate. Mol Microbiol. 2000; 36:651-61. [PubMed: 10844654]

53. Nikawa J, Tsukagoshi Y, Yamashita S. Isolation and characterization of two distinct myo-inositol transporter genes of Saccharomyces cerevisiae. J Biol Chem. 1991; 266:11184-91. [PubMed: 2040626]

54. Chang YY, Kennedy EP. Biosynthesis of phosphatidyl glycerolphosphate in Escherichia coli. J Lipid Res. 1967; 8:447-55. [PubMed: 4860577]

55. Chang SC, Heacock PN, Clancey CJ, Dowhan W. The PEL1 gene (renamed PGS1) encodes the phosphatidylglycerophosphate synthase of Saccharomyces cerevisiae. J Biol Chem. 1998; 273:9829-36. [PubMed: 9545322]

56. Osman C, Haag M, Wieland FT, Brugger B, Langer T. A mitochondrial phosphatase required for cardiolipin biosynthesis: the PGP phosphatase Gep4. EMBO J. 2010; 29:1976-87. [PubMed: 20485265]

57. Chang SC, Heacock PN, Mileykovskaya E, Voelker DR, Dowhan W. Isolation and characterization of the gene (CLS1) encoding cardiolipin synthase in Saccharomyces cerevisiae. J Biol Chem. 1998; 273:14933-41. [PubMed: 9614098]

58. Jiang F, Rizavi HS, Greenberg ML. Cardiolipin is not essential for the growth of Saccharomyces cerevisiae on fermentable or nonfermentable carbon sources. Mol Microbiol. 1997; 26:481-91. [PubMed: 9402019]

59. Tuller G, Hrastnik C, Achleitner G, Schiefthaler U, Klein F, Daum G. YDL142c encodes cardiolipin synthase (Clslp) and is nonessential for aerobic growth of Saccharomyces cerevisiae. FEBS Lett. 1998; 421:15-18. [PubMed: 9462830]

60. Letts VA, Klig LS, Bae-Lee M, Carman GM, Henry SA. Isolation of the yeast structural gene for the membrane-associated enzyme phosphatidylserine synthase. Proc Natl Acad Sci USA. 1983; 80:7279-83. [PubMed: 6316353]

61. Nikawa J, Tsukagoshi Y, Kodaki T, Yamashita S. Nucleotide sequence and characterization of the yeast PSS gene encoding phosphatidylserine synthase. Eur J Biochem. 1987; 167:7-12. [PubMed: 3040403]

62. Kiyono K, Miura K, Kushima Y, Hikiji T, Fukushima M, et al. Primary structure and product characterization of the Saccharomyces cerevisiae $\mathrm{CHO} 1$ gene that encodes phosphatidylserine synthase. J Biochem. 1987; 102:1089-100. [PubMed: 2830250]

63. Kanfer JN, Kennedy EP. Metabolism and function of bacterial lipids. II Biosynthesis of phospholipids in Escherichia coli. J Biol Chem. 1964; 239:1720-26. [PubMed: 14213340] 
64. Clancey CJ, Chang S-C, Dowhan W. Cloning of a gene (PSDI) encoding phosphatidylserine decarboxylase from Saccharomyces cerevisiae by complementation of an Escherichia coli mutant. J Biol Chem. 1993; 268:24580-90. [PubMed: 8227017]

65. Trotter PJ, Pedretti J, Voelker DR. Phosphatidylserine decarboxylase from Saccharomyces cerevisiae Isolation of mutants, cloning of the gene, and creation of a null allele. J Biol Chem. 1993; 268:21416-24. [PubMed: 8407984]

66. Trotter PJ, Pedretti J, Yates R, Voelker DR. Phosphatidylserine decarboxylase 2 of Saccharomyces cerevisiae Cloning and mapping of the gene, heterologous expression, and creation of the null allele. J Biol Chem. 1995; 270:6071-80. [PubMed: 7890740]

67. Bremer J, Greenberg DM. Methyl transfering enzyme system of microsomes in the biosynthesis of lecithin (phosphatidylcholine). Biochim Biophys Acta. 1961; 46:205-16.

68. Kodaki T, Yamashita S. Yeast phosphatidylethanolamine methylation pathway: cloning and characterization of two distinct methyltransferase genes. J Biol Chem. 1987; 262:15428-35. [PubMed: 2445736]

69. Summers EF, Letts VA, McGraw P, Henry SA. Saccharomyces cerevisiae cho2 mutants are deficient in phospholipid methylation and cross-pathway regulation of inositol synthesis. Genetics. 1988; 120:909-22. [PubMed: 3066687]

70. McGraw P, Henry SA. Mutations in the Saccharomyces cerevisiae OPI3 gene: effects on phospholipid methylation, growth, and cross pathway regulation of phospholipid synthesis. Genetics. 1989; 122:317-30. [PubMed: 2670666]

71. Nikawa J, Tsukagoshi Y, Yamashita S. Cloning of a gene encoding choline transport in Saccharomyces cerevisiae. J Bacteriol. 1986; 166:328-30. [PubMed: 3514579]

72. Nikawa J, Hosaka K, Tsukagoshi Y, Yamashita S. Primary structure of the yeast choline transport gene and regulation of its expression. J Biol Chem. 1990; 265:15996-6003. [PubMed: 2203793]

73. Kim K, Kim K-H, Storey MK, Voelker DR, Carman GM. Isolation and characterization of the Saccharomyces cerevisiae EKI1 gene encoding ethanolamine kinase. J Biol Chem. 1999; 274:14857-66. [PubMed: 10329685]

74. Hosaka K, Kodaki T, Yamashita S. Cloning and characterization of the yeast $C K I$ gene encoding choline kinase and its expression in Escherichia coli. J Biol Chem. 1989; 264:2053-59. [PubMed: 2536698]

75. Min-Seok R, Kawamata Y, Nakamura H, Ohta A, Takagi M. Isolation and characterization of ECT1 gene encoding CTP:phosphoethanolamine cytidylyltransferase of Saccharomyces cerevisiae. J Biochem. 1996; 120:1040-47. [PubMed: 8982874]

76. Tsukagoshi Y, Nikawa J, Yamashita S. Molecular cloning and characterization of the gene encoding cholinephosphate cytidylyltransferase in Saccharomyces cerevisiae. Eur J Biochem. 1987; 169:477-86. [PubMed: 2826147]

77. Hjelmstad RH, Bell RM. The $s n$-1,2-diacylglycerol ethanolaminephosphotransferase of Saccharomyces cerevisiaeIsolation of mutants and cloning of the EPT1 gene. J Biol Chem. 1988; 263:19748-57. [PubMed: 2848840]

78. Hjelmstad RH, Bell RM. sn-1,2-diacylglycerol choline- and ethanolaminephosphotransferases in Saccharomyces cerevisiaeNucleotide sequence of the EPT1 gene and comparison of the CPT1 and EPT1 gene products. J Biol Chem. 1991; 266:5094-103. [PubMed: 1848238]

79. Hjelmstad RH, Bell RM. Mutants of Saccharomyces cerevisiae defective in sn-1,2-diacylglycerol cholinephosphotransferase: isolation, characterization, and cloning of the CPT1 gene. J Biol Chem. 1987; 262:3909-17. [PubMed: 3029130]

80. Hjelmstad RH, Bell RM. The sn-1,2-diacylglycerol cholinephosphotransferase of Saccharomyces cerevisiaeNucleotide sequence, transcriptional mapping, and gene product analysis of the $C P T 1$ gene. J Biol Chem. 1990; 265:1755-64. [PubMed: 2153142]

81. Ozier-Kalogeropoulos O, Fasiolo F, Adeline M-T, Collin J, Lacroute F. Cloning, sequencing and characterization of the Saccharomyces cerevisiae URA7 gene encoding CTP synthetase. Mol Gen Genet. 1991; 231:7-16. [PubMed: 1753946]

82. Ozier-Kalogeropoulos O, Adeline M-T, Yang W-L, Carman GM, Lacroute F. Use of synthetic lethal mutants to clone and characterize a novel CTP synthetase gene in Saccharomyces cerevisiae. Mol Gen Genet. 1994; 242:431-39. [PubMed: 8121398] 
83. Han G-S, O’Hara L, Carman GM, Siniossoglou S. An unconventional diacylglycerol kinase that regulates phospholipid synthesis and nuclear membrane growth. J Biol Chem. 2008; 283:2043342. [PubMed: 18458075]

84. Han G-S, O'Hara L, Siniossoglou S, Carman GM. Characterization of the yeast DGK1-encoded CTP-dependent diacylglycerol kinase. J Biol Chem. 2008; 283:20443-53. [PubMed: 18458076]

85. Kohlwein SD. Triacylglycerol homeostasis: insights from yeast. J Biol Chem. 2010; 285:1566367. [PubMed: 20231294]

86. Carman, GM. Phosphatidylcholine metabolism in Saccharomyces cerevisiae. In: Vance, DE., editor. Phosphatidylcholine Metabolism. Boca Raton, FL: CRC Press; 1989. p. 165-83.

87. Patton-Vogt JL, Griac P, Sreenivas A, Bruno V, Dowd S, et al. Role of the yeast phosphatidylinositol/phosphatidylcholine transfer protein (Sec14p) in phosphatidylcholine turnover and INO1 regulation. J Biol Chem. 1997; 272:20873-83. [PubMed: 9252414]

88. Xie Z, Fang M, Rivas MP, Faulkner AJ, Sternweis PC, et al. Phospholipase D activity is required for suppression of yeast phosphatidylinositol transfer protein defects. Proc Natl Acad Sci USA. 1998; 95:12346-51. [PubMed: 9770489]

89. Rose K, Rudge SA, Frohman MA, Morris AJ, Engebrecht J. Phospholipase D signaling is essential for meiosis. Proc Natl Acad Sci USA. 1995; 92:12151-55. [PubMed: 8618862]

90. Waksman M, Eli Y, Liscovitch M, Gerst JE. Identification and characterization of a gene encoding phospholipase D activity in yeast. J Biol Chem. 1996; 271:2361-64. [PubMed: 8576189]

91. Zaccheo O, Dinsdale D, Meacock PA, Glynn P. Neuropathy target esterase and its yeast homologue degrade phosphatidylcholine to glycerophosphocholine in living cells. J Biol Chem. 2004; 279:24024-33. [PubMed: 15044461]

92. Fisher E, Almaguer C, Holic R, Griac P, Patton-Vogt J. Glycerophosphocholine-dependent growth requires Gde1p (YPL110c) and Git1p in Saccharomyces cerevisiae. J Biol Chem. 2005; 280:36110-17. [PubMed: 16141200]

93. Dowd SR, Bier ME, Patton-Vogt JL. Turnover of phosphatidylcholine in Saccharomyces cerevisiae: the role of the CDP-choline pathway. J Biol Chem. 2001; 276:3756-63. [PubMed: 11078727]

94. Fernandez-Murray JP, McMaster CR. Phosphatidylcholine synthesis and its catabolism by yeast neuropathy target esterase 1. Biochim Biophys Acta. 2007; 1771:331-36. [PubMed: 16731034]

95. Patton-Vogt J. Transport and metabolism of glycerophosphodiesters produced through phospholipid deacylation. Biochim Biophys Acta. 2007; 1771:337-42. [PubMed: 16781190]

96. Boumann HA, Damen MJ, Versluis C, Heck AJ, de Kruijff B, de Kroon AI. The two biosynthetic routes leading to phosphatidylcholine in yeast produce different sets of molecular species. Evidence for lipid remodeling. Biochemistry. 2003; 42:3054-59. [PubMed: 12627972]

97. de Kroon AI. Metabolism of phosphatidylcholine and its implications for lipid acyl chain composition in Saccharomyces cerevisiae. Biochim Biophys Acta. 2007; 1771:343-52. [PubMed: 17010666]

98. Kodaki T, Yamashita S. Characterization of the methyltransferases in the yeast phosphatidylethanolamine methylation pathway by selective gene disruption. Eur J Biochem. 1989; 185:243-51. [PubMed: 2684666]

99. Atkinson K, Fogel S, Henry SA. Yeast mutant defective in phosphatidylserine synthesis. J Biol Chem. 1980; 255:6653-61. [PubMed: 6771275]

100. Atkinson KD, Jensen B, Kolat AI, Storm EM, Henry SA, Fogel S. Yeast mutants auxotropic for choline or ethanolamine. J Bacteriol. 1980; 141:558-64. [PubMed: 6988386]

101. Trotter PJ, Voelker DR. Identification of a non-mitochondrial phosphatidylserine decarboxylase activity (PSD2) in the yeast Saccharomyces cerevisiae. J Biol Chem. 1995; 270:6062-70. [PubMed: 7890739]

102. Riekhof WR, Wu J, Gijon MA, Zarini S, Murphy RC, Voelker DR. Lysophosphatidylcholine metabolism in Saccharomyces cerevisiae: the role of P-type ATPases in transport and a broad specificity acyltransferase in acylation. J Biol Chem. 2007; 282:36853-61. [PubMed: 17951629]

103. Tamaki H, Shimada A, Ito Y, Ohya M, Takase J, et al. LPT1 encodes a membrane-bound $O$ acyltransferase involved in the acylation of lysophospholipids in the yeast Saccharomyces cerevisiae. J Biol Chem. 2007; 282:34288-98. [PubMed: 17890783] 
104. Tanaka K, Fukuda R, Ono Y, Eguchi H, Nagasawa S, et al. Incorporation and remodeling of extracellular phosphatidylcholine with short acyl residues in Saccharomyces cerevisiae. Biochim Biophys Acta. 2008; 1781:391-99. [PubMed: 18599377]

105. Stålberg K, Neal AC, Ronne H, Stahl U. Identification of a novel GPCAT activity and a new pathway for phosphatidylcholine biosynthesis in S. cerevisiae. J Lipid Res. 2008; 49:1794-806. [PubMed: 18430972]

106. McMaster CR, Bell RM. Phosphatidylcholine biosynthesis in Saccharomyces cerevisiaeRegulatory insights from studies employing null and chimeric $s n$-1,2-diacylglycerol choline- and ethanolaminephosphotransferases. J Biol Chem. 1994; 269:28010-16. [PubMed: 7961735]

107. Morash SC, McMaster CR, Hjelmstad RH, Bell RM. Studies employing Saccharomyces cerevisiae cpt1 and ept 1 null mutants implicate the $C P T 1$ gene in coordinate regulation of phospholipid biosynthesis. J Biol Chem. 1994; 269:28769-76. [PubMed: 7961831]

108. Santos-Rosa H, Leung J, Grimsey N, Peak-Chew S, Siniossoglou S. The yeast lipin Smp2 couples phospholipid biosynthesis to nuclear membrane growth. EMBO J. 2005; 24:1931-41. [PubMed: 15889145]

109. Li G, Chen S, Thompson MN, Greenberg ML. New insights into the regulation of cardiolipin biosynthesis in yeast: implications for Barth syndrome. Biochim Biophys Acta. 2007; 1771:43241. [PubMed: 16904369]

110. Loewen CJR, Gaspar ML, Jesch SA, Delon C, Ktistakis NT, et al. Phospholipid metabolism regulated by a transcription factor sensing phosphatidic acid. Science. 2004; 304:1644-47. [PubMed: 15192221]

111. White MJ, Hirsch JP, Henry SA. The OPI1 gene of Saccharomyces cerevisiae, a negative regulator of phospholipid biosynthesis, encodes a protein containing polyglutamine tracts and a leucine zipper. J Biol Chem. 1991; 266:863-72. [PubMed: 1985968]

112. Loewen CJR, Roy A, Levine TP. A conserved ER targeting motif in three families of lipid binding proteins and in Opilp binds VAP. EMBO J. 2003; 22:2025-35. [PubMed: 12727870]

113. Loewen CJR, Levine TP. A highly conserved binding site in vesicle-associated membrane protein-associated protein (VAP) for the FFAT motif of lipid-binding proteins. J Biol Chem. 2005; 280:14097-104. [PubMed: 15668246]

114. Nikawa J, Murakami A, Esumi E, Hosaka K. Cloning and sequence of the $S C S 2$ gene, which can suppress the defect of INO1 expression in an inositol auxotrophic mutant of Saccharomyces cerevisiae. J Biochem. 1995; 118:39-45. [PubMed: 8537323]

115. Kagiwada S, Hosaka K, Murata M, Nikawa J, Takatsuki A. The Saccharomyces cerevisiae SCS2 gene product, a homolog of a synaptobrevin-associated protein, is an integral membrane protein of the endoplasmic reticulum and is required for inositol metabolism. J Bacteriol. 1998; 180:1700-8. [PubMed: 9537365]

116. Kagiwada S, Zen R. Role of the yeast VAP homolog, Scs2p, in INO1 expression and phospholipid metabolism. J Biochem. 2003; 133:515-22. [PubMed: 12761300]

117. Sreenivas A, Patton-Vogt JL, Bruno V, Griac P, Henry SA. Role of phospholipase D (Pld1p) in growth, secretion, and regulation of membrane lipid synthesis in yeast. J Biol Chem. 1998; 273:16635-38. [PubMed: 9642212]

118. Han GS, Siniossoglou S, Carman GM. The cellular functions of the yeast lipin homolog Pah1p are dependent on its phosphatidate phosphatase activity. J Biol Chem. 2007; 282:37026-35. [PubMed: 17971454]

119. O’Hara L, Han GS, Peak-Chew S, Grimsey N, Carman GM, Siniossoglou S. Control of phospholipid synthesis by phosphorylation of the yeast lipin Pah1p/Smp2 $\mathrm{p} \mathrm{Mg}^{2+}$-dependent phosphatidate phosphatase. J Biol Chem. 2006; 281:34537-48. [PubMed: 16968695]

120. Iwanyshyn WM, Han GS, Carman GM. Regulation of phospholipid synthesis in Saccharomyces cerevisiae by zinc. J Biol Chem. 2004; 279:21976-83. [PubMed: 15028711]

121. Cowart LA, Obeid LM. Yeast sphingolipids: recent developments in understanding biosynthesis, regulation, and function. Biochim Biophys Acta. 2007; 1771:421-31. [PubMed: 16997623]

122. Pittet M, Conzelmann A. Biosynthesis and function of GPI proteins in the yeast Saccharomyces cerevisiae. Biochim Biophys Acta. 2007; 1771:405-20. [PubMed: 16859984] 
123. Kelley MJ, Bailis AM, Henry SA, Carman GM. Regulation of phospholipid biosynthesis in Saccharomyces cerevisiae by inositol. Inositol is an inhibitor of phosphatidylserine synthase activity. J Biol Chem. 1988; 263:18078-85. [PubMed: 2848023]

124. Murray JP, McMaster CR. Nte1p-mediated deacylation of phosphatidylcholine functionally interacts with Sec14p. J Biol Chem. 2005; 280:8544-52. [PubMed: 15611060]

125. Gaspar ML, Aregullin MA, Jesch SA, Henry SA. Inositol induces a profound alteration in the pattern and rate of synthesis and turnover of membrane lipids in Saccharomyces cerevisiae. J Biol Chem. 2006; 281:22773-85. [PubMed: 16777854]

126. Fernandez-Murray JP, Gaspard GJ, Jesch SA, McMaster CR. NTE1-encoded phosphatidylcholine phospholipase B regulates transcription of phospholipid biosynthetic genes. J Biol Chem. 2009; 284:36034-46. [PubMed: 19841481]

127. Jesch SA, Zhao X, Wells MT, Henry SA. Genome-wide analysis reveals inositol, not choline, as the major effector of Ino2p-Ino4p and unfolded protein response target gene expression in yeast. J Biol Chem. 2005; 280:9106-18. [PubMed: 15611057]

128. Nunez LR, Jesch SA, Gaspar ML, Almaguer C, Villa-Garcia M, et al. Cell wall integrity MAPK pathway is essential for lipid homeostasis. J Biol Chem. 2008; 283:34204-17. [PubMed: 18842580]

129. Eide DJ. Homeostatic and adaptive responses to zinc deficiency in Saccharomyces cerevisiae. J Biol Chem. 2009; 284:18565-69. [PubMed: 19363031]

130. Guerinot ML, Eide D. Zeroing in on zinc uptake in yeast and plants. Curr Opin Plant Biol. 1999; 2:244-49. [PubMed: 10375570]

131. Eide DJ. Multiple regulatory mechanisms maintain zinc homeostasis in Saccharomyces cerevisiae. J Nutr. 2003; 133(Suppl 1):S1532-35.

132. Kersting MC, Carman GM. Regulation of the Saccharomyces cerevisiae EKI1-encoded ethanolamine kinase by zinc depletion. J Biol Chem. 2006; 281:13110-16. [PubMed: 16551612]

133. Han S-H, Han G-S, Iwanyshyn WM, Carman GM. Regulation of the PIS1-encoded phosphatidyli-nositol synthase in Saccharomyces cerevisiae by zinc. J Biol Chem. 2005; 280:29017-24. [PubMed: 15980062]

134. Han G-S, Johnston CN, Carman GM. Vacuole membrane topography of the DPP1-encoded diacylglycerol pyrophosphate phosphatase catalytic site from Saccharomyces cerevisiae. J Biol Chem. 2004; 279:5338-45. [PubMed: 14630917]

135. Soto A, Carman GM. Regulation of the Saccharomyces cerevisiae CKI1-encoded choline kinase by zinc depletion. J Biol Chem. 2008; 283:10079-88. [PubMed: 18276583]

136. Opekarova M, Robl I, Tanner W. Phosphatidyl ethanolamine is essential for targeting the arginine transporter Can1p to the plasma membrane of yeast. Biochim Biophys Acta. 2002; 1564:9-13. [PubMed: 12100990]

137. Robl I, Grassl R, Tanner W, Opekarova M. Construction of phosphatidylethanolamine-less strain of Saccharomyces cerevisiae Effect on amino acid transport. Yeast. 2001; 18:251-60. [PubMed: 11180458]

138. Zhang W, Campbell HA, King SC, Dowhan W. Phospholipids as determinants of membrane protein topology. Phosphatidylethanolamine is required for the proper topological organization of the $\gamma$-aminobutyric acid permease (GabP) of Escherichia coli. J Biol Chem. 2005; 280:2603238. [PubMed: 15890647]

139. Chen CC, Wilson TH. The phospholipid requirement for activity of the lactose carrier of Escherichia coli. J Biol Chem. 1984; 259:10150-58. [PubMed: 6381481]

140. Bogdanov M, Dowhan W. Lipid-assisted protein folding. J Biol Chem. 1999; 274:36827-30. [PubMed: 10601231]

141. Zhang W, Bogdanov M, Pi J, Pittard AJ, Dowhan W. Reversible topological organization within a polytopic membrane protein is governed by a change in membrane phospholipid composition. $\mathrm{J}$ Biol Chem. 2003; 278:50128-35. [PubMed: 14525982]

142. Yang W-L, McDonough VM, Ozier-Kalogeropoulos O, Adeline M-T, Flocco MT, Carman GM. Purification and characterization of CTP synthetase, product of the URA7gene in Saccharomyces cerevisiae. Biochemistry. 1994; 33:10785-93. [PubMed: 8075080] 
143. Nadkarni AK, McDonough VM, Yang W-L, Stukey JE, Ozier-Kalogeropoulos O, Carman GM. Differential biochemical regulation of the URA7- and URA8-encoded CTP synthetases from Saccharomyces cerevisiae. J Biol Chem. 1995; 270:24982-88. [PubMed: 7559626]

144. McDonough VM, Buxeda RJ, Bruno MEC, Ozier-Kalogeropoulos O, Adeline M-T, et al. Regulation of phospholipid biosynthesis in Saccharomyces cerevisiae by CTP. J Biol Chem. 1995; 270:18774-80. [PubMed: 7642527]

145. Ostrander DB, O'Brien DJ, Gorman JA, Carman GM. Effect of CTP synthetase regulation by CTP on phospholipid synthesis in Saccharomyces cerevisiae. J Biol Chem. 1998; 273:189929001. [PubMed: 9668079]

146. Kent C, Carman GM. Interactions of pathways for phosphatidylcholine metabolism, CTP synthesis, and secretion through the Golgi apparatus. Trends Biochem Sci. 1999; 24:146-50. [PubMed: 10322420]

147. Wu W-I, Carman GM. Regulation of phosphatidate phosphatase activity from the yeast Saccharomyces cerevisiae by phospholipids. Biochemistry. 1996; 35:3790-96. [PubMed: 8620000]

148. Homann MJ, Henry SA, Carman GM. Regulation of CDP-diacylglycerol synthase activity in Saccharomyces cerevisiae. J Bacteriol. 1985; 163:1265-66. [PubMed: 2993242]

149. Klig LS, Homann MJ, Kohlwein SD, Kelley MJ, Henry SA, Carman GM. Saccharomyces cerevisiae mutant with a partial defect in the synthesis of CDP-diacylglycerol and altered regulation of phospholipid biosynthesis. J Bacteriol. 1988; 170:1878-86. [PubMed: 2832385]

150. Shen H, Dowhan W. Reduction of CDP-diacylglycerol synthase activity results in the excretion of inositol by Saccharomyces cerevisiae. J Biol Chem. 1996; 271:29043-48. [PubMed: 8910557]

151. Gaynor PM, Carman GM. Phosphatidylethanolamine methyltransferase and phospholipid methyltransferase activities from Saccharomyces cerevisiae Enzymological and kinetic properties. Biochim Biophys Acta. 1990; 1045:156-63. [PubMed: 2198947]

152. Karin M, Hunter T. Transcriptional control by protein phosphorylation: signal transmission from the cell surface to the nucleus. Curr Biol. 1995; 5:747-57. [PubMed: 7583121]

153. Calkhoven $\mathrm{CF}, \mathrm{Ab}$ G. Multiple steps in the regulation of transcription-factor level and activity. Biochem J. 1996; 317:329-42. [PubMed: 8713055]

154. Komeili A, O'Shea EK. Roles of phosphorylation sites in regulating activity of the transcription factor Pho4. Science. 1999; 284:977-80. [PubMed: 10320381]

155. Liu C, Yang Z, Yang J, Xia Z, Ao S. Regulation of the yeast transcriptional factor PHO2 activity by phosphorylation. J Biol Chem. 2000; 275:31972-78. [PubMed: 10884387]

156. Kaffman A, Rank NM, O’Neill EM, Huang LS, O’Shea EK. The receptor Msn5 exports the phosphorylated transcription factor Pho4 out of the nucleus. Nature. 1998; 396:482-86. [PubMed: 9853758]

157. Hung W, Olson KA, Breitkreutz A, Sadowski I. Characterization of the basal and pheromonestimulated phosphorylation states of Ste12p. Eur J Biochem. 1997; 245:241-51. [PubMed: 9151949]

158. Broach JR, Deschenes RJ. The function of $R A S$ genes in Saccharomyces cerevisiae. Adv Cancer Res. 1990; 54:79-139. [PubMed: 2153328]

159. Thevelein JM. Signal transduction in yeast. Yeast. 1994; 10:1753-90. [PubMed: 7747517]

160. Levin DE, Fields FO, Kunisawa R, Bishop JM, Thorner J. A candidate protein kinase C gene, $P K C 1$, is required for the $S$. cerevisiae cell cycle. Cell. 1990; 62:213-24. [PubMed: 2196995]

161. Levin DE, Bartlett-Heubusch E. Mutants in the $S$. cerevisiae PKC1 gene display a cell cyclespecific osmotic stability defect. J Cell Biol. 1992; 116:1221-29. [PubMed: 1740473]

162. Glover CV 3rd. On the physiological role of casein kinase II in Saccharomyces cerevisiae. Prog Nucl Acid Res Mol Biol. 1998; 59:95-133.

163. Litchfield DW. Protein kinase CK2: structure, regulation and role in cellular decisions of life and death. Biochem J. 2003; 369:1-15. [PubMed: 12396231]

164. Guerra B, Issinger OG. Protein kinase CK2 and its role in cellular proliferation, development and pathology. Electrophoresis. 1999; 20:391-408. [PubMed: 10197447] 
165. Chen-Wu JL, Padmanabha R, Glover CV. Isolation, sequencing, and disruption of the $C K A 1$ gene encoding the alpha subunit of yeast casein kinase II. Mol Cell Biol. 1988; 8:4981-90. [PubMed: 3062376]

166. Reed JC, Bidwai AP, Glover CVC. Cloning and disruption of $C K B 2$, the gene encoding for the 32-kDa regulatory $\beta^{\prime}$-subunit of Saccharomyces cerevisiae casein kinase II. J Biol Chem. 1994; 269:18192-200. [PubMed: 8027080]

167. Bidwai AP, Reed JC, Glover CV. Cloning and disruption of $C K B 1$, the gene encoding the 38-kDa $\beta$ subunit of Saccharomyces cerevisiae casein kinase II (CKII). Deletion of CKII regulatory subunits elicits a salt-sensitive phenotype. J Biol Chem. 1995; 270:10395-404. [PubMed: 7737972]

168. Padmanabha R, Glover CVC. Casein kinase II of yeast contains two distinct $a$ polypeptides and an unusually large $\beta$ subunit. J Biol Chem. 1987; 262:1829-35. [PubMed: 3468112]

169. Enserink JM, Kolodner RD. An overview of Cdk1-controlled targets and processes. Cell Div. 2010; 5:11. [PubMed: 20465793]

170. Klig LS, Homann MJ, Carman GM, Henry SA. Coordinate regulation of phospholipid biosynthesis in Saccharomyces cerevisiae: pleiotropically constitutive opi1 mutant. J Bacteriol. 1985; 162:1135-41. [PubMed: 3888957]

171. Sreenivas A, Villa-Garcia MJ, Henry SA, Carman GM. Phosphorylation of the yeast phospholipid synthesis regulatory protein Opi1p by protein kinase C. J Biol Chem. 2001; 276:29915-23. [PubMed: 11395523]

172. Sreenivas A, Carman GM. Phosphorylation of the yeast phospholipid synthesis regulatory protein opi1p by protein kinase A. J Biol Chem. 2003; 278:20673-80. [PubMed: 12668681]

173. Chang Y-F, Carman GM. Casein kinase II phosphorylation of the yeast phospholipid synthesis transcription factor Opilp. J Biol Chem. 2006; 281:4754-61. [PubMed: 16407309]

174. Wagner C, Dietz M, Wittmann J, Albrecht A, Schuller HJ. The negative regulator Opi1 of phospholipid biosynthesis in yeast contacts the pleiotropic repressor Sin3 and the transcriptional activator Ino2. Mol Microbiol. 2001; 41:155-66. [PubMed: 11454208]

175. Heyken WT, Repenning A, Kumme J, Schuller HJ. Constitutive expression of yeast phospholipid biosynthetic genes by variants of Ino2 activator defective for interaction with Opi1 repressor. Mol Microbiol. 2005; 56:696-707. [PubMed: 15819625]

176. Yamashita S, Nikawa J. Phosphatidylserine synthase from yeast. Biochim Biophys Acta. 1997; 1348:228-35. [PubMed: 9370337]

177. Bae-Lee M, Carman GM. Phosphatidylserine synthesis in Saccharomyces cerevisiae Purification and characterization of membrane-associated phosphatidylserine synthase. J Biol Chem. 1984; 259:10857-62. [PubMed: 6088519]

178. Natter K, Leitner P, Faschinger A, Wolinski H, McCraith S, et al. The spatial organization of lipid synthesis in the yeast Saccharomyces cerevisiae derived from large scale green fluorescent protein tagging and high resolution microscopy. Mol Cell Proteomics. 2005; 4:662-72. [PubMed: 15716577]

179. Williams JG, McMaster CR. Scanning alanine mutagenesis of the CDP-alcohol phosphotransferase motif of Saccharomyces cerevisiae cholinephosphotransferase. J Biol Chem. 1998; 273:13482-87. [PubMed: 9593682]

180. Choi H-S, Han G-S, Carman GM. Phosphorylation of yeast phosphatidylserine synthase by protein kinase A. Identification of $\mathrm{Ser}^{46}$ and $\mathrm{Ser}^{47}$ as major sites of phosphorylation. J Biol Chem. 2010; 285:11526-36. [PubMed: 20145252]

181. Kinney AJ, Carman GM. Phosphorylation of yeast phosphatidylserine synthase in vivo and in vitro by cyclic AMP-dependent protein kinase. Proc Nat Acad Sci USA. 1988; 85:7962-66. [PubMed: 2847149]

182. Carman GM, Han G-S. Regulation of phospholipid synthesis in yeast. J Lipid Res. 2009; 50:S6973. [PubMed: 18955729]

183. Taylor FR, Parks LW. Triacylglycerol metabolism in Saccharomyces cerevisiae relation to phospholipid synthesis. Biochim Biophys Acta. 1979; 575:204-14. [PubMed: 389291] 
184. Lamping E, Luckl J, Paltauf F, Henry SA, Kohlwein SD. Isolation and characterization of a mutant of Saccharomyces cerevisiae with pleiotropic deficiencies in transcriptional activation and repression. Genetics. 1995; 137:55-65. [PubMed: 8056324]

185. Long CW, Pardee AB. Cytidine triphosphate synthetase of Escherichia coli B. Purification and kinetics. J Biol Chem. 1967; 242:4715-21. [PubMed: 4862983]

186. Levitzki A, Koshland DE Jr. Role of an allosteric effector. Guanosine triphosphate activation in cytosine triphosphate synthetase. Biochemistry. 1972; 11:241-46. [PubMed: 4550559]

187. Yang W-L, Carman GM. Phosphorylation and regulation of CTP synthetase from Saccharomyces cerevisiae by protein kinase A. J Biol Chem. 1996; 271:28777-83. [PubMed: 8910520]

188. Yang W-L, Bruno MEC, Carman GM. Regulation of yeast CTP synthetase activity by protein kinase C. J Biol Chem. 1996; 271:11113-19. [PubMed: 8626655]

189. Pappas A, Yang W-L, Park T-S, Carman GM. Nucleotide-dependent tetramerization of CTP synthetase from Saccharomyces cerevisiae. J Biol Chem. 1998; 273:15954-60. [PubMed: 9632643]

190. Park T-S, Ostrander DB, Pappas A, Carman GM. Identification of $\mathrm{Ser}^{424}$ as the protein kinase A phosphorylation site in CTP synthetase from Saccharomyces cerevisiae. Biochemistry. 1999; 38:8839-48. [PubMed: 10393561]

191. Choi M-G, Park TS, Carman GM. Phosphorylation of Saccharomyces cerevisiae CTP synthetase at $\mathrm{Ser}^{424}$ by protein kinases A and $\mathrm{C}$ regulates phosphatidylcholine synthesis by the CDP-choline pathway. J Biol Chem. 2003; 278:23610-16. [PubMed: 12709422]

192. Park T-S, O’Brien DJ, Carman GM. Phosphorylation of CTP synthetase on $\mathrm{Ser}^{36}, \mathrm{Ser}^{330}, \mathrm{Ser}^{354}$, and $\mathrm{Ser}^{454}$ regulates the levels of CTP and phosphatidylcholine synthesis in Saccharomyces cerevisiae. J Biol Chem. 2003; 278:20785-94. [PubMed: 12670958]

193. Kim K-H, Voelker DR, Flocco MT, Carman GM. Expression, purification, and characterization of choline kinase, product of the CKI gene from Saccharomyces cerevisiae. J Biol Chem. 1998; 273:6844-52. [PubMed: 9506987]

194. Kennedy, EP. The biosynthesis of phospholipids. In: Op den Kamp, JAF.; Roelofsen, B.; Wirtz, KWA., editors. Lipids and Membranes: Past, Present and Future. Amsterdam: Elsevier Sci; 1986. p. 171-206.

195. Wittenberg J, Kornberg A. Choline phosphokinase. J Biol Chem. 1953; 202:431-44. [PubMed: 13061469]

196. Peisach D, Gee P, Kent C, Xu Z. The crystal structure of choline kinase reveals a eukaryotic protein kinase fold. Structure. 2003; 11:703-13. [PubMed: 12791258]

197. Brenner S. Phosphotransferase sequence homology. Nature. 1987; 329:21. [PubMed: 3041224]

198. Yuan C, Kent C. Identification of critical residues of choline kinase A2 from Caenorhabditis elegans. J Biol Chem. 2004; 279:17801-9. [PubMed: 14960577]

199. Yamashita S, Hosaka K. Choline kinase from yeast. Biochim Biophys Acta. 1997; 1348:63-69. [PubMed: 9370317]

200. Ishidate K. Choline/ethanolamine kinase from mammalian tissues. Biochim Biophys Acta. 1997; 1348:70-78. [PubMed: 9370318]

201. Kim K-H, Carman GM. Phosphorylation and regulation of choline kinase from Saccharomyces cerevisiae by protein kinase A. J Biol Chem. 1999; 274:9531-38. [PubMed: 10092638]

202. Choi M-G, Kurnov V, Kersting MC, Sreenivas A, Carman GM. Phosphorylation of the yeast choline kinase by protein kinase C. Identification of $\mathrm{Ser}^{25}$ and $\mathrm{Ser}^{30}$ as major sites of phosphorylation. J Biol Chem. 2005; 280:26105-12. [PubMed: 15919656]

203. Yu Y, Sreenivas A, Ostrander DB, Carman GM. Phosphorylation of Saccharomyces cerevisiae choline kinase on $\mathrm{Ser}^{30}$ and $\mathrm{Ser}^{85}$ by protein kinase A regulates phosphatidylcholine synthesis by the CDP-choline pathway. J Biol Chem. 2002; 277:34978-86. [PubMed: 12105205]

204. Lin Y-P, Carman GM. Purification and characterization of phosphatidate phosphatase from Saccharomyces cerevisiae. J Biol Chem. 1989; 264:8641-45. [PubMed: 2542283]

205. Carman GM, Han G-S. Phosphatidic acid phosphatase, a key enzyme in the regulation of lipid synthesis. J Biol Chem. 2008; 284:2593-97. [PubMed: 18812320] 
206. Ubersax JA, Woodbury EL, Quang PN, Paraz M, Blethrow JD, et al. Targets of the cyclindependent kinase Cdk1. Nature. 2003; 425:859-64. [PubMed: 14574415]

207. Ptacek J, Devgan G, Michaud G, Zhu H, Zhu X, et al. Global analysis of protein phosphorylation in yeast. Nature. 2005; 438:679-84. [PubMed: 16319894]

208. Dephoure N, Howson RW, Blethrow JD, Shokat KM, O'Shea EK. Combining chemical genetics and proteomics to identify protein kinase substrates. Proc Natl Acad Sci USA. 2005; 102:17940 45. [PubMed: 16330754]

209. Mah AS, Elia AE, Devgan G, Ptacek J, Schutkowski M, et al. Substrate specificity analysis of protein kinase complex Dbf2-Mob1 by peptide library and proteome array screening. BMC Biochem. 2005; 6:22. [PubMed: 16242037]

210. Davis FM, Tsao TY, Fowler SK, Rao PN. Monoclonal antibodies to mitotic cells. Proc Natl Acad Sci USA. 1983; 80:2926-30. [PubMed: 6574461]

211. Siniossoglou S, Santos-Rosa H, Rappsilber J, Mann M, Hurt E. A novel complex of membrane proteins required for formation of a spherical nucleus. EMBO J. 1998; 17:6449-64. [PubMed: 9822591]

212. Karanasios E, Han G-S, Xu Z, Carman GM, Siniossoglou S. A phosphorylation-regulated amphipathic helix controls the membrane translocation and function of the yeast phosphatidate phosphatase. Proc Natl Acad Sci USA. 2010; 107:17539-44. [PubMed: 20876142]

213. Toke DA, Bennett WL, Dillon DA, Chen X, Oshiro J, et al. Isolation and characterization of the Saccharomyces cerevisiae DPP1 gene encoding for diacylglycerol pyrophosphate phosphatase. J Biol Chem. 1998; 273:3278-84. [PubMed: 9452443]

214. Toke DA, Bennett WL, Oshiro J, Wu WI, Voelker DR, Carman GM. Isolation and characterization of the Saccharomyces cerevisiae LPP1 gene encoding a $\mathrm{Mg}^{2+}$-independent phosphatidate phosphatase. J Biol Chem. 1999; 273:14331-38. [PubMed: 9603941] 


\section{SUMMARY POINTS}

1. Phospholipid synthesis genes containing a $\mathrm{UAS}_{\mathrm{INO}}$ element are transcriptionally activated by the Ino2p-Ino4p heterodimer, which is repressed by Opilp.

2. The nuclear localization and repressor function of Opilp is regulated by its interaction with Scs2p and PA at the nuclear/ER membrane.

3. $\mathrm{PA}$ is a phospholipid precursor and also plays a major role as a signaling molecule in the regulation of phospholipid synthesis gene expression.

4. PA phosphatase and DAG kinase play major roles in regulating PA levels.

5. Genetic and biochemical mechanisms are interrelated to control membrane phospholipid synthesis.

6. Phosphorylation regulates, either positively or negatively, the function of Opi1p and the activity and localization of key phospholipid synthesis enzymes. 


\section{FUTURE ISSUES}

1. Structures of phospholipid synthesis enzymes and regulatory proteins need to be solved to elucidate the molecular mechanisms of catalytic function, membrane association, and gene expression.

2. Phosphorylation regulates the functions of Opilp and phospholipid synthesis enzymes. The molecular mechanisms for these regulations need further examination. Information on the physiological conditions that stimulate and repress phosphorylation/dephosphorylation by specific protein kinases and phosphatases is needed.

3. Data from the global analyses of gene and protein expressions, protein modifications, and metabolites (e.g., lipidomics) need to be evaluated and integrated for designing novel research approaches to better understand the regulation of phospholipid synthesis and its relationship with other metabolic pathways.

4. Some reactions in phospholipid synthesis are catalyzed by more than one enzyme (e.g., glycerol-3-phosphate and lysoPA acyltransferases, PS decarboxylase, CTP synthetase, and PA phosphatase). In the case of PS decarboxylase, enzyme activity is required for functions in different cellular compartments. For enzymes (e.g., acyltransferases and CTP synthetase) localized in the same cellular compartment, the reason for redundancy is not obvious and needs to be addressed.

5. Some enzymes participate in multiple biosynthetic pathways. For example, the product (DAG) of the PA phosphatase reaction is used for the synthesis of phospholipids and TAG, whereas the product (CTP) of the CTP synthetase reaction is used for the synthesis of phospholipids and nucleic acids. The mechanisms that control the utilization of the products for different metabolic processes warrant further investigations. 


\section{YEAST GENE/PROTEIN NOMENCLATURE}

$S$. cerevisiae genes are designated by three uppercase italicized letters followed by a number (e.g., PIS1 for phosphatidylinositol synthase 1), ideally describing the biochemical/molecular function of their protein products. Lowercase italicized letters designate a recessive mutation in the gene (e.g., pis1). Some yeast genes (e.g., CHO1 and OPI3) are named after their mutant phenotypes (e.g., cho1 mutants require choline and opi3 mutants overproduce and excrete inositol, respectively) or other genetic phenotypes. For genes that have several names (e.g., the gene for PS synthase has two names: $C H O 1$ and $P S S 1$ ) because of independent identification and naming, the standard name is the one generally described first, and the other names are designated as aliases (see the Saccharomyces Genome Database, http://www.yeastgenome.org/). The protein product of a yeast gene is designated by the gene acronym followed by the letter p (e.g., Pis1p, Cholp, Opi3p). 


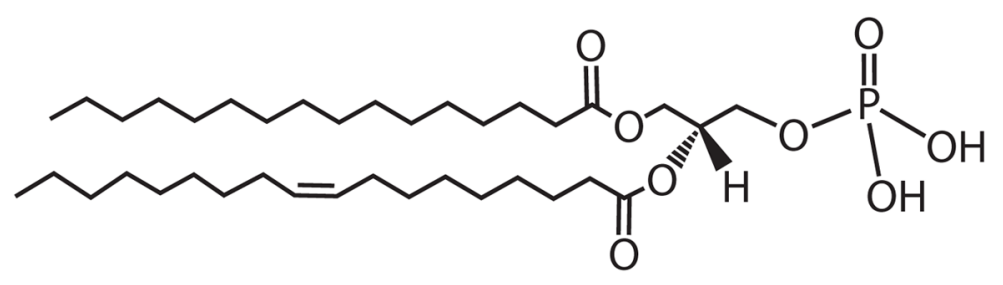

Figure 1.

Basic phospholipid structure. The diagram shows the structure of phosphatidate (PA), the phospholipid precursor, with fatty acyl groups containing 16 carbon atoms (position 1) and 18 carbon atoms with one double bond (position 2). 


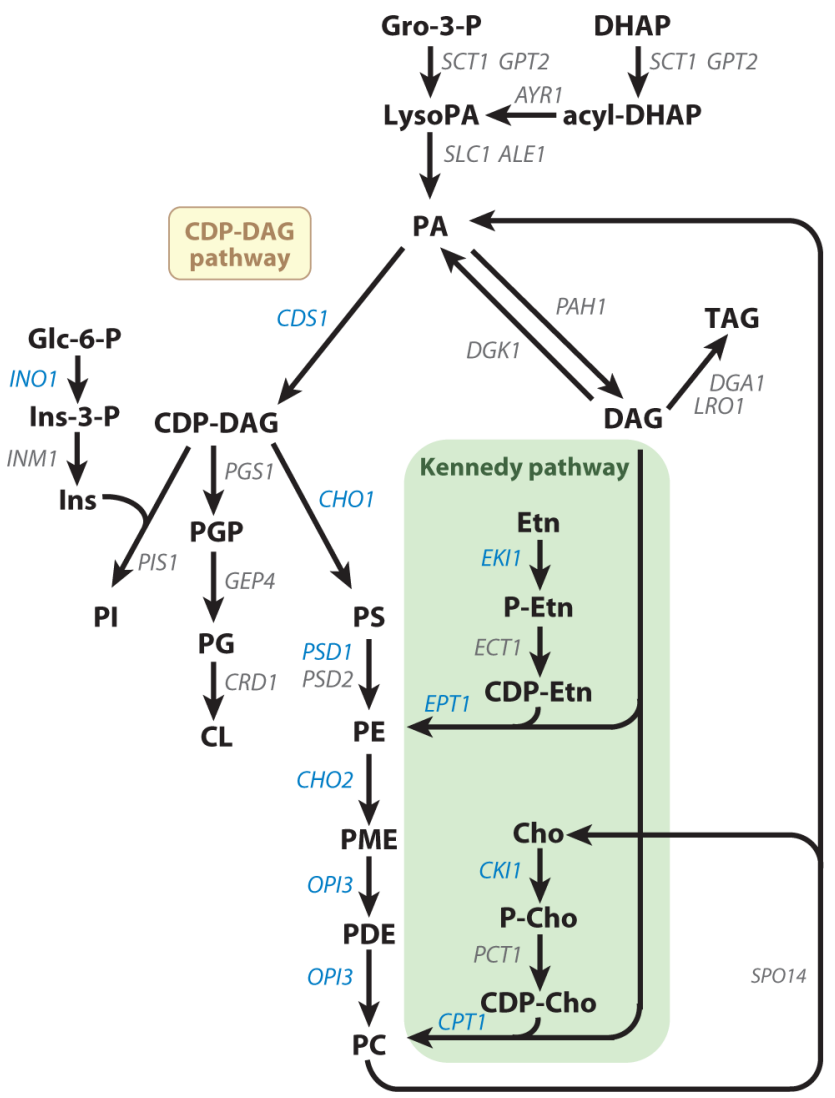

Figure 2.

Phospholipid synthesis pathways in $S$. cerevisiae. The pathways shown for the synthesis of phospholipids include the relevant steps discussed in this review. The genes that are known to encode enzymes catalyzing individual steps in the lipid synthesis pathways are indicated.

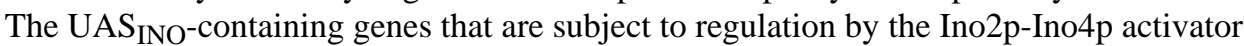
complex and the Opi1p repressor are shown (blue). Abbreviations: CDP-DAG, CDPdiacylglycerol; Cho, choline; CL, cardiolipin; Gro, glycerol; DHAP, dihydroxyacetone phosphate; Etn, ethanolamine; Glc, glucose; Ins, inositol; PA, phosphatidate; PC, phosphatidylcholine; PE, phosphatidylethanolamine; PG, phosphatidylglycerol; PGP, phosphatidylglycerophosphate; PDE, phosphatidyldimethylethanolamine; PI, phosphatidylinositol; PME, phosphatidylmonomethylethanolamine; PS, phosphatidylserine; TAG, triacylglycerol; $\mathrm{UAS}_{\mathrm{INO}}$, an inositol-responsive upstream activating sequence. 
a Inositol depletion, zinc supplementation, and exponential phase

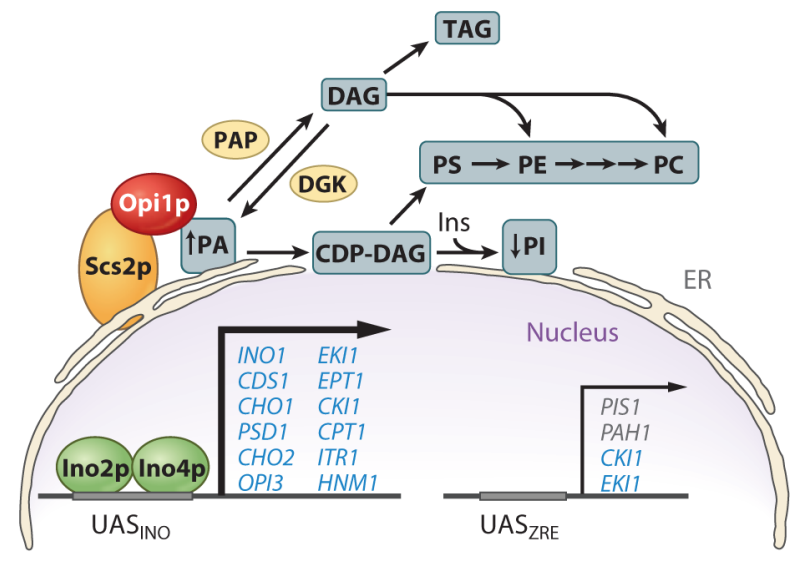

b Inositol supplementation, zinc depletion,
and stationary phase

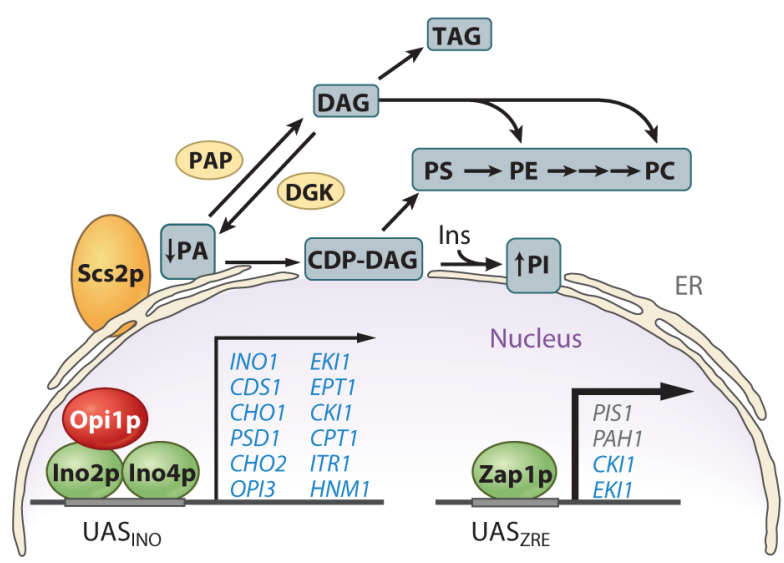

Figure 3.

Model for the phosphatidate (PA)-mediated regulation of $\mathrm{UAS}_{\mathrm{INO}}$-containing phospholipid synthesis genes. (a) Under growth conditions whereby the levels of PA are increased, the Opi1p repressor is tethered to the nuclear/endoplasmic reticulum (ER) membrane via interactions with Scs2p and PA, allowing the maximal expression (bold arrow) of $\mathrm{UAS}_{\mathrm{INO}^{-}}$ containing genes (blue) by the Ino2p-Ino4p activator complex. (b) Under growth conditions whereby the levels of PA are reduced, Opi1p is dissociated from the nuclear/ER membrane and enters into the nucleus, where it binds to Ino2p and attenuates (thin arrow) the transcriptional activation by the Ino2p-Ino4p complex. The PA level in the cell is decreased by the stimulation of phosphatidylinositol (PI) synthesis in response to inositol (Ins) supplementation and by the Zap1p-mediated induction of PIS1 that occurs in response to zinc depletion. The regulations that occur in response to zinc depletion and stationary phase occur in the absence of inositol supplementation. PA phosphatase (PAP) and DAG kinase (DGK) play major roles in the regulation of PA content and thereby in the transcriptional regulation of $\mathrm{UAS}_{\mathrm{INO}}$-containing genes. CDP-DAG, CDP-diacylglycerol; PC, phosphatidylcholine; PE, phosphatidylethanolamine; PS, phosphatidylserine; TAG, triacylglycerol; $\mathrm{UAS}_{\mathrm{INO}}$, inositol-responsive element; $\mathrm{UAS}_{\mathrm{ZRE}}$, zinc-responsive element; Zap1p, a transcriptional activator protein that interacts with the $U_{\text {ARE }}$. 
Opi1p

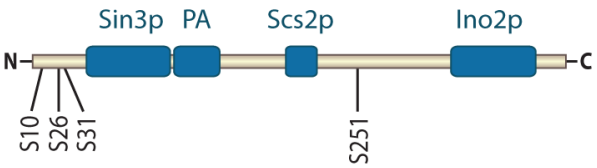

PS synthase

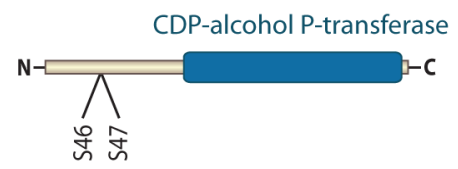

CTP synthetase

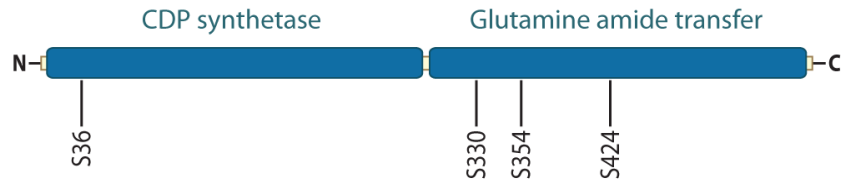

Choline kinase

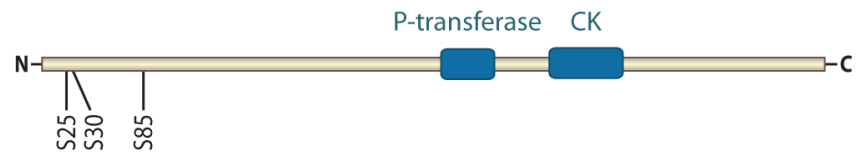

PA phosphatase

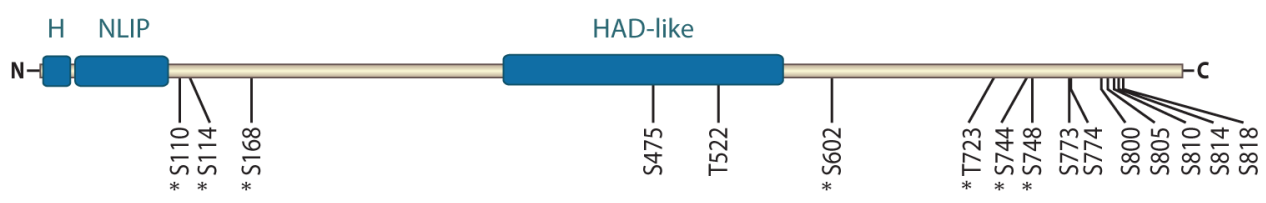

Figure 4.

Domain structures and phosphorylation sites of Opi1p and phospholipid synthesis enzymes. Opi1p (with 404 amino acids) contains domains for interactions with Sin3p, phosphatidate (PA), Scs2p, and Ino2p. It also contains Ser (S) residues that are sites for phosphorylation by protein kinases A and C and casein kinase II. Phosphatidylserine (PS) synthase (with 277 amino acids) contains a CDP-alcohol phosphotransferase (P-transferase) domain and Ser residues for phosphorylation by protein kinase A. CTP synthetase (with 579 amino acids) contains the CTP synthetase and glutamine amide transfer domains as well as the Ser residues for phosphorylation by protein kinases A and C. Choline kinase (with 582 amino acids) contains the phosphotransferase and choline kinase (CK) domains as well as the Ser residues for phosphorylation by protein kinases A and C. PA phosphatase (with 862 amino acids) contains an amphipathic helix (H), NLIP and haloacid dehalogenase (HAD)-like domains, and $16 \mathrm{Ser} / \mathrm{Thr}$ residues for phosphorylation. The seven sites denoted with an asterisk are within the minimal Ser/Thr-Pro motif that is a target of cyclin-dependent kinases. 